\title{
Art for Audience's Sake: \\ How can audience-centric art interpretation enhance meaning, diversity and accessibility?
}

\author{
Nicola Caldwell \\ Victoria University of Wellington
}

2018

A dissertation submitted to Victoria University of Wellington in partial fulfilment of the requirements for the degree of Master of Museum and Heritage Studies. 



\section{Abstract}

Art interpretation can make or break an individual's experience in an art gallery. At its best, it can inspire a sense of connection, expanded understanding and excitement but, at its worst, it can leave visitors feeling baffled, frustrated or out of their depth. International literature indicates public responsibility, engagement and accessibility are essential to the new museology and new museum ethics, with audience-focused interpretation practices being led by heritage and museum professionals. Public art galleries also have a responsibility to create inclusive interpretation, yet, especially in New Zealand, the way they go about this is largely ungoverned, under-theorised and lacking systematic evaluation. Interpretation is one of the primary functions of public art galleries, therefore understanding how and why interpretation is currently done is essential in developing a critically reflective practice. Inspired by models overseas and addressing this lack of research about the topic, especially in the New Zealand context, this dissertation explores how galleries might enhance meaning, diversity and accessibility through audience-centric art interpretation.

Taking three small-medium public art galleries in the Wellington region - the Dowse Art Museum, Pātaka Art + Museum and the Adam Art Gallery - as case studies, this dissertation investigates current practices, philosophies and training available to and demonstrated by gallery staff. Employing qualitative data collection methods, semi-structured interviews with the director and senior curator of each gallery were conducted using iterative, grounded theory approaches. As well as examining a wide range of international theoretical and professional literature, the research explores understandings of interpretation, audience needs and motivations, and strategies for interpretive planning and policy.

This dissertation addresses a gap in the local literature by providing original research on interpretive practice. The findings reveal that, while well intentioned and conscious of the democratic function of interpretation, local interpretation practice is informal and personal, lacking institutional structure, planning and critical evaluation. Furthermore, the analysis and discussion lead to the development of a set of principles and strategies for an audience-centric approach which have global applicability. Art interpretation is a young field still developing a shared body of knowledge, language and practice. This study argues that embedding social responsibility, collaboration and critical reflection is essential to the development of an audience-centric, innovative professional practice. 



\section{Acknowledgements}

First, a massive thank you to my supervisors, Dr Conal McCarthy and Helen Lloyd, for your expert guidance, support, insight and encouragement. Thank you for sharing your passion for audience engagement, your perspectives as industry insiders, for reining me in when necessary and for inspiring me to develop my argument into a call for action. This dissertation is the richer for your input.

I sincerely thank my interview participants, Christina Barton, Stephen Cleland, Reuben Friend, Mark Hutchins-Pond, Courtney Johnston and Melanie Oliver. Thank you for generously giving your time and for sharing your perspectives, knowledge and experiences with candour and openness. Your involvement was crucial to this dissertation.

To all those in the Museum and Heritage Studies programme, Dr Lee Davidson, Dr Conal McCarthy, Robyn Cockburn, Annie Mercer and my fellow classmates, thank you for making this one of the best educational experiences. You have all taught me so much and contributed to my growth as a person and as a professional.

I want to thank, from the bottom of my heart, my family, friends and flatmates who have been a great source of comfort, encouragement, inspiration and strength - I could not have completed this dissertation without your support. In particular Ella, Nathalie, Kate and Francesco. Love you all!

To my mum, Dawn, thank you for your unconditional love and support always.

To my dad, John, in my heart, thank you for instilling a sense of what is important in life and a curiosity for understanding how things work.

And to my brother, Andrew, thank you for being you and always being there for me. 



\section{Table of Contents}

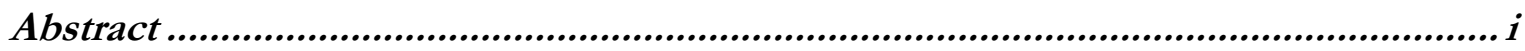

Acknowledgements ......................................................................................................iii

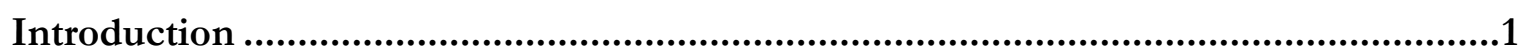

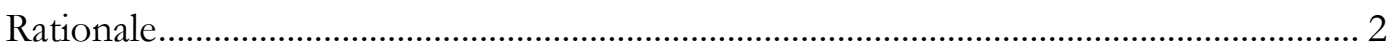

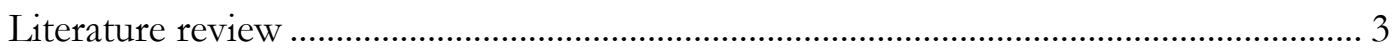

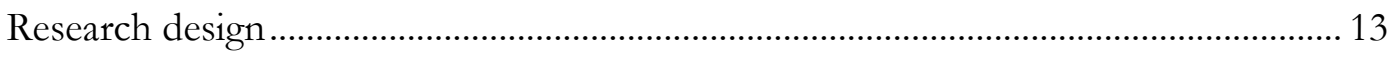

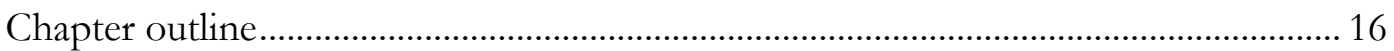

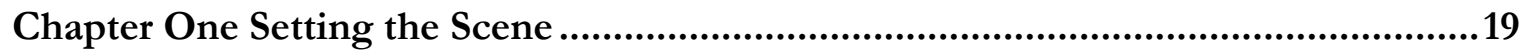

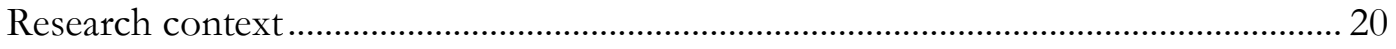

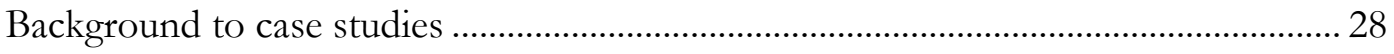

Chapter Two Interpretation in Practice.....................................................................33

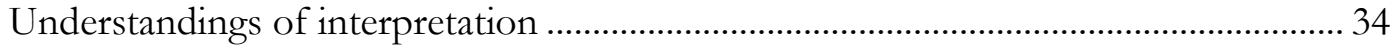

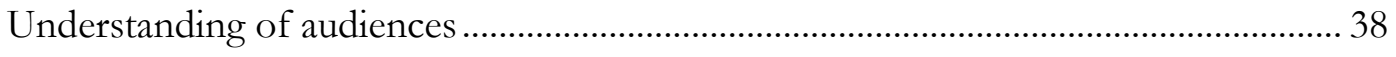

Development of interpretation .......................................................................................... 40

Interpretive planning and strategic documents ............................................................ 44

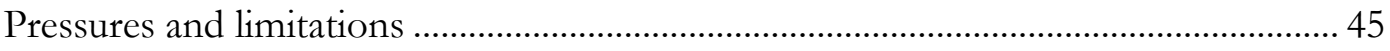

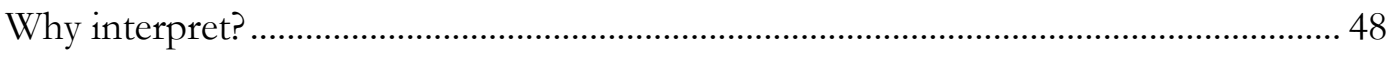

Chapter Three Towards Audience-centric Art Interpretation.....................................53

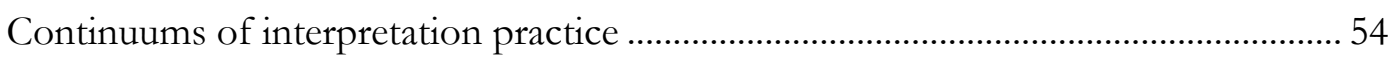

From the new museology to local interpretive practice .................................................... 57

Why galleries need to put audiences at the heart of their work ...................................... 59

How might audience-centric art interpretation be embedded in gallery practice? ...... 60

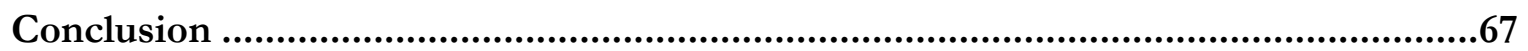

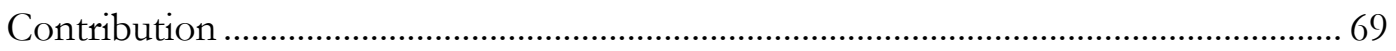

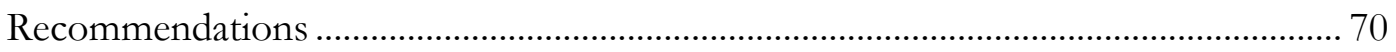

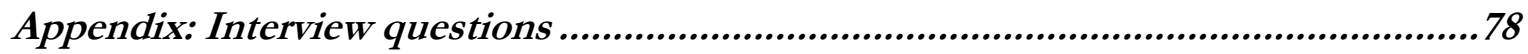

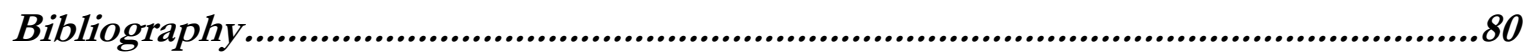





\section{Introduction}


Art has the power to enthral, challenge, stimulate, connect and offer critique. However, these qualities require the support of gallery interpretation to make them accessible to broad audiences and fulfil the needs of individuals and communities. Art interpretation is an area of museology that is in its academic infancy, only recently developing a common set of experiences, vocabulary and frameworks. Given that interpretation is one of the primary activities of public art galleries, understanding how and why interpretation is done by practitioners can give insight into professional gallery practice and the intended visitor experience. Through my research, I explore current knowledge, understanding and practices of art interpretation in small-medium New Zealand public art galleries and present an argument for taking an audience-centric approach to interpretation. As this dissertation will show, I believe that everyone has the capacity to appreciate, and be transformed by, their experiences of art and that galleries have a responsibility to create engaging, diverse and meaningful experiences of art for all.

\section{Rationale}

Interpretation in New Zealand public art galleries is an under-theorised topic, lacking evidencebased evaluation of galleries' meaningful engagement with their audiences. Encounters with art are complex, personal experiences that vary based on innumerable variables such as education, interests, taste, personality and motivations - so how do galleries cater for the diversity of their audiences? This task could be overwhelming and daunting. However, I see it as an opportunity to be smart about creating accessible, diverse and meaningful art interpretation.

Interpretation covers all aspects of how art is encountered by audiences, from the perception of the institution, to the layout, design, content and wall labels, to the choice of exhibitions and accompanying programmes. Exhibitions are inherently collaborative, so having a strong public mission and interpretive strategy should help keep diverse staff working towards the same goal. However, does this happen in practice? Especially in small galleries, where staffing and funding is limited, do staff incorporate or even consider their audiences' needs and motivations when planning exhibitions?

These are questions I have been grappling with as a young professional entering the gallery and museum sector. As an avid art lover, I am often disappointed by my experiences in art galleries, where the interpretation has sometimes been elitist, arrogant or simply boring. I am passionate about the idea that everyone can appreciate, and get something meaningful out of, their encounters with art. This research aims to identify strategies for achieving this. I believe interpretation is the key to creating entry points for those who are uninitiated, as well as to extend and challenge those who bring prior knowledge. By examining current practice and looking to international examples 
of innovation, I aim to demonstrate the importance of audience-centric art interpretation in creating diverse, accessible and meaningful gallery experiences.

\section{Literature review}

In this review, I draw from diverse bodies of literature including museum and heritage studies, art history, education, heritage, curatorial and interpretation sources. Focusing on Western literature, mainly from the United States and the United Kingdom, it is useful to note the word 'museum' in the US is used interchangeably for both museums and art galleries, whereas in the UK the two are understood as separate. As the practices and intellectual frameworks of art galleries are inextricably linked with those of museums, I begin with a brief overview of the changing purpose and function of museums in the last fifty years. The new museology offers models for audience-focused approaches to participation and meaning-making in cultural organisations. I contextualise an audience-centric model by exploring theories of visitor experience, motivations and identities. I then seek to unpack what interpretation and interpretive planning entails before focusing in on art interpretation specifically.

\section{New Museology}

Collections-based art museums, focusing solely on scholarship, research and preservation, have slowly been disappearing, making way for more visitor-centred approaches. Our modern conception of museums and galleries is that they are places for informal learning, social interaction and leisure activities. ${ }^{1}$ In addition, the volume and diversity of audiences has also exploded, requiring museum professionals to think differently about their mission and delivery. ${ }^{2}$

Eilean Hooper-Greenhill grapples with the new museological changes in art galleries in her article "Changing Values in the Art Museum: rethinking communication and learning" (2000). She argues that people perceive galleries to be even more special and set apart than museums as they appear to attract more 'cultured and sophisticated people.' She sees new museological practices as

1 Malcolm Foley and Gayle McPherson, 'Museums as Leisure', International Journal of Heritage Studies 6, no. 2 (2000): 161-174; Barbara Kirshenblatt-Gimblett, Destination Culture: Tourism, Museums, and Heritage (University of California Press, 1998); Emma Barker, ed., Contemporary Cultures of Display, Art and Its Histories (New Haven \& London: Yale University Press, 1999); Kathleen McLean, 'Museum Exhibitions and the Dynamics of Dialogue', Daedalus 128, no. 3 (1999): 83-107.

2 Gail Anderson, Reinventing the Museum: The Evolving Conversation on the Paradigm Shift, 2nd ed.. (Lanham, Md.: AltaMira Press, 2012); Graham Black, The Engaging Museum: Developing Museums for Visitor Involvement (Psychology Press, 2005); Peter Vergo, The New Museology (London: Reaktion Books, 1989); Marcella D. Wells, Barbara H. Butler, and Judith Koke, Interpretive Planning for Museums: Integrating Visitor Perspectives in Decision Making (Walnut Creek, Calif.: Left Coast Press, Inc, 2012). 
offering solutions for overcoming visitor threshold fear and making galleries more democratic. In her book, Museums and the Interpretation of Visual Culture (2003), Hooper-Greenhill asks questions about the ways in which museums construct meaning, value and knowledge by the selection, placement and interpretation of objects. She teases out the dialogue between institutions and audiences in the construction of meaning by testing theory in case studies. Hers is a useful model for exploring interpretation in a cross-disciplinary study.

Peter Vergo's edited collection, The New Museology (1989), is an essential text in understanding the changes in museum theory and practice and it signals a growing self-awareness through critical discourse. Philip Wright's chapter, “The Quality of Visitors' Experiences in Art Museums”, is of particular relevance to my study. Critical of the balance of priorities in art museums, Wright argues curators are concerned more with the art historical cannon than addressing the audiences' understanding of art. He points out that interpretation in galleries should not be primarily directed towards art specialists, but at general, non-art specialist audiences. ${ }^{3}$ Wright also stands firmly against the oft' cited argument that art can and should be left to speak for itself. Artworks are made within social, political, cultural and economic contexts that are rendered invisible in a gallery context. Furthermore, if artworks do indeed 'speak for themselves' then why do scholars dedicate such energies to understanding, interpreting, categorising and valuing art? While Wright's is an older text, his articulation of the need for accessible art interpretation for non-specialist audiences is still current and yet to be resolved in our modern galleries.

\section{Understanding the visitor experience}

It is important to address visitor motivations, identities and mean-making, but a comprehensive study of this was outside the scope of my research. Fortunately, there is excellent research to draw upon. ${ }^{4}$ International visitor studies in museums and art galleries offer useful frameworks for addressing diverse audiences. Theorist John Falk has developed a model based around museums and galleries fulfilling identity-related needs. These needs have a bearing on visitors' reasons for going to museums, how they judge the success of those visits and the way they construct meaning out of their experiences. Falk has developed five identity-related categories of visitors: explorers, facilitators, professional/hobbyists, experience seekers and rechargers. ${ }^{5}$ This is

3 Philip Wright, 'The Quality of Visitors' Experiences in Art Museums', The New Museology, 1989, 120.

4 Lee Davidson, 'Visitor Studies: Toward a Culture of Reflective Practice and Critical Museology for the VisitorCentered Museum', in The International Handbooks of Museum Studies (John Wiley \& Sons, Ltd, 2013).

5 John H. Falk, Identity and the Museum Visitor Experience (Routledge, 2012), 324-25. 
a useful model for galleries to consider in understanding the diversity of their audiences based on values and needs rather than demographics.

Judy Rand's Visitors' Bill of Rights is a useful checklist of audience requirements that galleries should meet to facilitate an audience-centric approach. Rand identifies 'a list of important human needs, seen from the visitor's point of view,' including: comfort, orientation, welcome/belonging, enjoyment, the want to have a good time, socialising, respect, communication, learning, choice and control, challenge and confidence, and revitalisation. ${ }^{6}$ Rand's list of visitor needs offers simple, easy-to-follow guidelines that are essential to consider when developing audience-centric interpretation. Local scholar Lee Davidson also discusses the importance of visitor research in audience-centred museums and has carried out extensive research at our national museum. ${ }^{7}$

\section{Interpretation in museums and heritage sites}

New Zealand practitioner Kerry Jimson argues that interpretation is essential in helping visitors create meaning, thus opening up a world of possibilities. Jimson cautions that interpretation is not a simple task, that it can 'misfire, be misguided, patronise, or simply not work' but that good interpretation can 'excite, inspire, and motivate. It can galvanise perception, provoke action and shift attitudes'. ${ }^{8}$ As the purview of a number of roles (including concept developer, curator, writer and educator), interpretation is a function involving 'aspects of communicating, explaining, clarifying, facilitating and opening things up to greater understanding. ${ }^{9}$ Jimson's explanation of the role and function of interpretation is useful in a general way, but as his focus is on museums, the specific needs and dilemmas intrinsic to art galleries have not been addressed.

Lisa Roberts' ideologies of interpretation in her text, Changing Practices of Interpretation (2012), extend on from those of Wright and Jimson. She sees interpretation as a way to empower visitors, giving them control of their meaning-making by offering guides and tools for looking, questioning and expressing responses. She also argues that it is important to make the interpretive construction clear to audiences, so they understand that every exhibition is fundamentally interpretive, that it is

6 Judy Rand, 'The Visitors' Bill of Rights', in Reinventing the Museum: The Evolving Conversation on the Paradigm Shift, 2nd ed. (Lanham, New York, Toronto and Plymouth, UK: Altamira Press, 2012), 315-16.

7 Davidson, 'Visitor Studies'; Lee Davidson and Pamela Sibley, 'Audiences at the "New" Museum: Visitor Commitment, Diversity and Leisure at the Museum of New Zealand Te Papa Tongarewa', Visitor Studies 14, no. 2 (1 July 2011): 176-94.

8 Kerry Jimson, 'Translating Museum Meanings: A Case for Interpretation', in The International Handbooks of Museum Studies, 2015, 529.

9 Jimson, 529. 
authored and is only one person's or institution's view of the subject. By acknowledging that meaning is affected by the presentation and context of the objects, the interpretation gives a platform for critique, disagreement and dialogue between experts and the audience. Roberts reiterates Wright's point that labels need to offer a way in for non-experts or risk being elitist. By acknowledging and responding to audiences' needs, galleries will become more inclusive and multivocal. Roberts suggests that museums and galleries have an ethical responsibility to represent nonspecialist knowledge and make explicit the construction of exhibitions and their meanings. She states powerfully that 'the work of interpretation becomes an act of empowerment, because it provides visitors with both the knowledge and the consent to engage in critical dialogue about the messages museums present'. ${ }^{10}$

Cheryl Meszaros, in her chapter "Interpreting the Art Museum: Between the familiar and the unfamiliar" (2011), uses Jacques Derrida's concept of 'hauntology' to explore the ghosts of past interpretive strategies throughout the history of museums and their displays. Her aim is to make interpretive authority visible and to critique the pedagogies of display. In the eighteenth century, interpretive authority was possessed by "the connoisseur" - predominantly educated, upper class white men who passed judgement on what was 'good,' 'original' or 'authentic.' Meszaros suggests it is possible to exorcize this ghost by exposing taste as a cultural construct. However, she is mindful that 'the connoisseur, the art historian, the specialists - these are not enemies, they hold deep and profound knowledge about collections, and they hold interpretive repertoires that activate meaning. ${ }^{11}$ In the nineteenth century, interpretive authority shifted to the "author" or producer of cultural objects - privileging the intention of the artist above all else. However, this model does not account for collaboration and collective practice and by the twentieth century the authority of the "author" was ousted by a close reading of "the text itself". 12 The internal coherence and meaning of a work was thought to be able to be decoded reliably and that there was a singular truth to be gained. This swiftly fell under the weight of multiple interpretations that differed wildly even within peer groups and was replaced with interpretive authority lying with the "individual". The paradox for museums is reconciling the desire to convey knowledge and 'educate' the public,

10 Lisa C. Roberts, 'Changing Practices of Interpretation', in Reinventing the Museum: The Evolving Conversation on the Paradigm Shift, 2nd ed. (Lanham, New York, Toronto and Plymouth, UK: Altamra Press, 2012), 158.

11 Cheryl Meszaros, 'Interpretation and the Art Museum: Between the Familiar and the Unfamiliar', in Museum Gallery Interpretation and Material Culture, Routledge Research in Museum Studies; 2 (New York: Routledge, 2011), 43.

12 Roland Barthes, 'The Death of the Author', The Book History Reader 2 (2002): 277-280; Amanda Wayers, 'Models, modes and exhibitionary practices: from anteriority to immanence in exhibition development' (Victoria University of Wellington, 2007). 
whilst also respecting the autonomy of the individual. Meszaros describes how meaning is not made in a vacuum, but that people rely on their interactions, prior knowledge and 'received' ideas and language. Thus, our current interpretive phase of "relationality" where there is a 'concern with recognising and naming the forces in culture that shape the opinions, thoughts and feelings we call our own. ... П]n this context, we ask not "what is my opinion?" but rather, "how did I come to have that opinion?"'13 She suggests museums shift from constructivist models of education to those of critical pedagogy, commenting that 'educators must make content meaningful to the individual in order to make it critical so that it will be transformative'. ${ }^{14}$

\section{Institutional conundrums - educators vs. curators}

The question of purpose in museums and galleries is a thorny one, with a divide between those concerned with collections and research and those who see audience and education as the primary function. A visitor-centred approach is often championed by educators, due to the nature of their work, whereas curatorial staff often favour a collection-centred approach. Karen Grøn acknowledges the divide between collections- and audience-focused staff, adding that this discrepancy is only compounded by the functions of curators and educators being held within two separate departments. She suggests that methodologies of active participation, investigation and discovery 'can potentially offer richer experiences and reach wider audiences' than the traditional 'white cube' gallery experiences. ${ }^{15}$ Understanding that museums and galleries operate within the wider leisure sector, Grøn outlines how competition with other interactive and immersive activities means that art museums cannot take their audiences for granted. She suggests museums could benefit from incorporating Pine and Gilmore's experience economy theory and George Hein's constructivist learning theory. The Experience Economy (1999) is a way of understanding consumer engagement for products and businesses, incorporating two axes - absorption to immersion, and passive participation to active participation, dividing a circle into four quadrants: entertainment, educational, aesthetic and escapist. This model corresponds with Hein's constructivist learning theory, where learning is increased through participation and personal meaning-making. Grøn draws a connection between experience and learning, commenting that projects where the audience is empowered in a playful, safe and challenging way [...] visitors can experience and learn through reconstruction of their personal knowledge, engaging with museums objects while they

13 Meszaros, 'Interpretation and the Art Museum: Between the Familiar and the Unfamiliar', 45.

14 Meszaros, 45.

15 Karen Grøn, 'Empower the Audience! How Art Museums Can Become Enriching Creative Spaces for a Wider Audience through Deliberate and Strategic Use of Experience and Learning Theories', in Museum Gallery Interpretation and Material Culture, Routledge Research in Museum Studies; 2 (New York: Routledge, 2011), 204. 
socialise - and have fun'. ${ }^{16}$ By breaking down barriers between curating and education, it is not only possible to reinterpret collections but also the institution itself, a task that is immensely rewarding for museum professionals as well as audiences. ${ }^{17}$

From her experience at the Victoria and Albert Museum as Head of Gallery Interpretation, Evaluation and Resources, Juliette Fritsch describes the underlying assumptions concerning the 'nature of the relationship between interpretation and learning, as understood by those who work on exhibition development and design'. ${ }^{18}$ By conducting interviews with staff, Frisch identified areas of confusion and unease with certain terms using broad linguistic analysis. She found that while staff were able to easily define education and interpretation in terms of the construction and communication of museum knowledge, they were less able to identify differences between the two concepts. Fritsch also found that the curators, designers and project managers saw interpretation as holistically integrated into their professional roles whereas education was seen as a 'tack on' to the core museum functions and something separate from exhibition development. This is an important finding to keep in mind when dealing with how interpretation, education and learning are understood by museum and gallery staff. Fritsch concludes that interpretation is a process that begins long before an exhibition is encountered by the public and that the staff involved form interpretive communities in their own right.

\section{Interpretation in heritage literature}

Interpretive planning is an area that has been developed extensively by the heritage sector. Books such as Freeman Tilden's seminal work Interpreting our Heritage (1957), Russell Staiffs Heritage and Tourism: Place, Encounter, Engagement (2013), Peter Howard's Heritage: Management, Interpretation, Identity (2003) and the edited volume Heritage Interpretation (2006) are useful resources in understanding other disciplinary approaches to interpretation. The heritage sector has a strong focus on audience value and how interactions with cultural heritage sites can enrich visitors' lives - aspects that can and should be translated to art interpretation.

Sam H. Ham's Interpretation: Making a Difference on Purpose (2013) describes current heritage interpretation philosophies, capturing changes in interpretive pedagogies and methods for developing interpretive products, with a focus on free-choice learning, visitor behaviour and compelling meaning-making. Chapters cover such topics as communication, TORE (theme,

16 Grøn, 216.

17 McLean, 'Museum Exhibitions and the Dynamics of Dialogue'.

18 Juliette Fritsch, Museum Gallery Interpretation and Material Culture, Routledge Research in Museum Studies; 2 (New York: Routledge, 2011), 234. 
organised, relevant, enjoyable), interpretation endgames (provocation, teaching, entertainment), making a difference and theme development. Ham offers both a philosophical grounding in the purpose of interpretation (or how to think about interpretation), as well as real world examples and information about bow-to do interpretation. Ham creates his own definition of interpretation:

Interpretation is a mission-based approach to communication aimed at provoking in audiences the discovery of personal meaning and the forging of personal connections with things, places, people and concepts. ${ }^{19}$

His whole philosophy is based around making a connection on purpose - that interpretation needs to have a clear function, its audience in mind and a message to get across. While a message may be less straightforward for art than heritage, where environmental activism is the aim - evident in Tilden's 'through interpretation, understanding; through understanding, appreciation; through appreciation, protection, ${ }^{20}$ there are still valid lessons that can be applied to art interpretation.

Larry Beck and Ted Cable's book, The Gifts of Interpretation - Fifteen Guiding Principles for interpreting Nature and Culture (2011), discusses the authors' thoughts, views and guiding philosophies about the act and process of interpretation. With a focus on cultural heritage interpretation, Beck and Cable have framed their ideas into a series of philosophical gifts offered by good interpretation, including: spark, revelation, story, provocation, wholeness, targeted programmes, personalising the past, illumination through technology, precision, professionalism, interpretive writing, relationship, beauty, joy, passion and, finally, hope. ${ }^{21}$ It encourages interpreters to think and, as Ham describes in the foreword, 'they provoke their readers to do their own thinking - to struggle with inconsistencies, to challenge dogma, and to question what might previously have been their own philosophical comfort zones. ${ }^{22}$ Along the same lines as Tilden's famous mantra 'not instruction, but provocation, ${ }^{23}$ this book stands as an exemplary guide not only to audience-centric interpretive practice but also as an example of how clear and simple philosophies can function as catalysts for change.

19 Sam H. Ham, Interpretation: Making a Difference on Purpose (Golden, Colorado: Fulcrum Publishing, 2013 ), 8.

20 Freeman Tilden, Interpreting Our Heritage: Principles and Practices for Visitor Services in Parks, Museums, and Historic Places (Durham, NC: University of North Carolina Press, 1957).

21 Larry Beck and Ted T Cable, The Gifts of Interpretation: Fifteen Guiding Principles for Interpreting Nature and Culture (Urbana, IL: Sagamore Publishing, 2011).

22 Beck and Cable, viii.

23 Tilden, Interpreting Our Heritage, 59. 


\section{Interpreting art}

What makes interpreting art in galleries different from that of interpreting artefacts in museums or interpreting heritage at historic sites? There are many similarities in that interpretation aims to communicate contextual information and offer an entry point into subject matter. However, art and art history have a variety of disciplinary quirks which mean that art interpretation tends to be more complex. Artistic production deals with the whole gamut of human experience as well as aesthetics, materiality and representation. There is a whole world of art historical interrelationships, politics and economics, meaning that each individual artwork and each exhibition has a complex back- story. The complexity of art and its relationships often causes visitors to feel baffled and out of their depth - this makes good art interpretation essential.

Christopher Whitehead's book, Interpreting Art in Museums and Galleries (2012), deals elegantly and clearly with the practices, discourses and problems surrounding the interpretation of art. Whitehead is an advocate for audience-centric art interpretation, although he does not use that exact terminology. He clearly states the necessity of art interpretation for non-specialist audiences in similar terms to Wright and Roberts. While his volume is not a guide about how to do art interpretation, it is a philosophical discussion of the theoretical and practical, offering critique and historical overview. He states that 'any talk of art interpretation is necessarily complex, for art itself is complex and practically impossible to define in itself. ${ }^{24}$ Whitehead explores the political, sociological and historical dimensions of art interpretation, traditions and psychology of display and discusses the moral and ethical responsibilities of practitioners and institutions creating interpretation, making it an essential text for art interpretation professionals.

As much of the interpretive work in small-medium galleries is controlled by curators, it is especially important for curatorial staff to consider their audiences when conceptualising, designing and evaluating exhibitions. As art historian, Alessandro Mauro, observes:

In a sense, it is the visitors who make the exhibition, by creating their own itinerary. We may try to guide them, to map out a route, to tell a story, but the fact is that any curator who spends a quarter of an hour in an exhibition will see that visitors use the space differently, in ways that the curator has never even thought of. They may reverse the order, linger here, pass by there. ${ }^{25}$

24 Christopher Whitehead, Interpreting Art in Museums and Galleries, 1st ed. (Abingdon, Oxon, England; New York, NY: Routledge, 2012), 3.

25 Alessandro Mauro, 'The Deviation from the Norm: Curating Photographs in the Internet Age', in Photoshow: Landmark Exhibitions That Defined the History of Photography Alessandra MAURO | Asia Art Archive (Rome: Contrasto, 2014), 12. 
Addressing a range of audiences, from art experts to children, is a challenge for museums and galleries, begging the question 'who is interpretation for?' Sue Latimer addresses a circular set of arguments that are often brought to bear on art interpretation. She paraphrases these as:

- The art should speak for itself - you don't need interpretation.

- These labels are patronising.

- These labels are simplistic - we need art historical facts.

- Art is a complex and intuitive thing - you can't pin it down to didactic facts.

- You can't tell people how to look at a work of art.

- You need expert knowledge of art history to enjoy a gallery. ${ }^{26}$

These criticisms often come from other experts, art historians and critics but they rarely offer practical solutions about what art interpretation should look like and who it should address. Latimer cites research about visitor responses to art which 'demonstrated that art appreciation is an acquired skill, but galleries and art experts continue to assume a level of prior knowledge and experience that excludes many visitors'. ${ }^{27}$ In her experience with a refurbishment project at Kelvingrove Art Gallery and Museum in Glasgow, Latimer describes the interpretive choices that were made for the museum to be more inclusive of its diverse local population. Key principles included writing 'immediately accessible and engaging text, addressing a defined audience and not assuming prior knowledge,. ${ }^{28}$ The success of the principles also lay in the fact that they were applied across the institution, regardless of collection or theme. Despite negative feedback from art critics about this approach to the art galleries, Kelvingrove now attracts the most diverse audience of any museum of its size in Western Europe. Latimer sums up their approach with a quote from heritage interpretation theorist Sam Ham: 'Interpretation is a provocation, not instruction. In other words, we're not trying to teach anything to anybody; we're simply trying to provoke them to deep thought about something. ${ }^{29}$ By providing stimulating introductory material for those unfamiliar with art, using a friendly tone and employing story to engage visitors, Kelvingrove succeeded in reaching new audiences.

26 Sue Latimer, 'Art for Whose Sake?', in Museum Gallery Interpretation and Material Culture, Routledge Research in Museum Studies; 2 (New York: Routledge, 2011), 72.

27 Latimer, 73.

28 Latimer, 68.

29 Latimer, 75; Ham, Interpretation. 
Interpreting art is not a new idea or area of study and there has been a considerable amount written on the subject within the disciplines of art history and education. ${ }^{30}$ Terry Barret's Interpreting Art: Reflecting, Wondering, and Responding (2002) is written as a guide for engaging with works of art that is accessible for a variety of educated readers. While it assumes a basic level of art knowledge or interest, it is written in an engaging and informative way that avoids being either patronising or oblique. Barrett comments that art can generate many meanings and often ones unintended by the artist. Art interpretation is a call to viewers to look actively, generate meaning and take artists' marks seriously. Barrett's clear and progressive interpretive explanations, from valuing art to multiple interpretations, voices and reflections, as well as principles for interpreting art, provides one of the most useful and comprehensive texts in this area. Barrett uses examples of art interpretation for a range of art styles, attitudes and mediums to illustrate his points about multiple meanings, judgement and appreciation of art.

Irina Costache's textbook, The Art of Understanding Art (2012), offers further strategies and case studies for art interpretive practice. Addressed mainly towards students and educators, this book gives an overview of the whole process of art - from making, to dissemination, analysis and interpretation. Coming from an art historical background, Costache covers methodologies such as classification, archival research and art historical literature that are useful in understanding the construction of meaning present in traditional art interpretation. Costache also offers a hopeful outlook for the future of art interpretation, stating that:

Understanding art will teach you to react constructively to new ideas and divergent perspectives and value diverse cultures and various customs. It will stimulate your mind and your eyes: you will look more attentively and think more creatively. [...] Art is important and gratifying. ${ }^{31}$

These types of texts offer practitioners examples of different styles of interpretation and an understanding of how practices have changed over time and shaped viewers' readings of an artwork. It is always useful to be reminded that interpretation is a powerful construction.

30 Kate Booth, 'The Democratization of Art: A Contextual Approach', Visitor Studies 17, no. 2 (2014): 207-221; Rika Burnham and Elliott Kai-Kee, Teaching in the Art Museum: Interpretation as Experience (Getty Publications, 2011); Shelley Ruth Butler and Erica Lehrer, eds., Curatorial Dreams: Critics Imagine Exbibitions (McGill-Queen's University Press, 2016); Irina Dana Costache, The Art of Understanding Art (Chichester, West Sussex, UK; Malden, MA, Chichester [England] ; Malden, Mass.: Wiley-Blackwell, 2012); Grøn, 'Empower the Audience! How Art Museums Can Become Enriching Creative Spaces for a Wider Audience through Deliberate and Strategic Use of Experience and Learning Theories'; Veronica Sekules, Maria Xanthoudaki, and Les Tickle, Researching Visual Arts Education in Museums and Galleries: An International Reader. (Springer Science, 2003).

31 Costache, The Art of Understanding Art, xv. 
Nina Simon's The Art of Relevance (2016) is a beautifully written, inspiring and down-to- earth guide to thinking about audience-centric museums and galleries. By framing her arguments around relevance, Simon asks museum practitioners to understand and act on their public mission, advocating for social inclusion and community outreach to connect meaningfully with audiences. ${ }^{32}$ Unlocking transformational experiences for all, whether they are first time visitors, dedicated friends of the institution, funders or staff, Simon argues, should be the purpose of the museum's work. As director of the Santa Cruz Museum of Art and History, Simon shares her journey of revitalising and making relevant her museum's offerings to her community, opening doors and creating connections - all useful lessons that could be applied to New Zealand art galleries. Simon not only works through the practical problems of creating institutional change but also offers inspiration and insight into why this change is necessary. In her words:

I believe relevance unlocks new ways to build deep connections with people who don't immediately self-identify with our work. I believe relevance is the key to a locked room where meaning lives. We just have to find the right keys, the right doors, and the humanity and courage to open them. ${ }^{33}$

Simon sees galleries as holding great treasures, but believes that it is up to institutions to make those treasures relevant to people's lives, create connections, encourage personal meaning-making and to invite as diverse an audience as possible into the gallery - exactly what I hope to encourage with my research.

\section{Research design}

My literature review demonstrates the benefits of and necessity for art institutions to think about their audience's profile, needs and motivations when planning exhibitions and interpreting art and gives this dissertation a strong analytical framework through which to tackle the overarching research question:

\section{How might small-medium New Zealand public art galleries enhance the diversity and accessibility of visitor experiences through a more audience-centric approach to art interpretation?}

To give some background, the following is an explanation of my choices. Firstly, I focus on smallmedium galleries as they often do not have the staff, time or resources to develop interpretation

32 Nina Simon, The Participatory Museum (Santa Cruz, CA: Museum 2.0, 2010).

33 Nina Simon, The Art of Relevance (Santa Cruz, CA: Museum 2.0, 2016), 23. 
plans with their audiences, do consultation or delve into extensive research about visitor behaviour and needs. I do not want to imply that these galleries do not think about their audiences - they do - just that they could benefit from specific research into their practices to encourage critical reflection and help prioritise their audience's needs.

Secondly, by concentrating on diversity and accessibility, my aim was to explore the importance of facilitating personal meaning-making and non-expert experience. While physical accessibility in galleries is essential, it is outside the scope of my study. Instead, the focus is on intellectual and emotional accessibility - promoting connections between art and audiences.

Finally, the use of audience-centric, as opposed to visitor-centric, is an important distinction in communicating the intention behind this research project. I not only hope to encourage galleries to think about the experience of those who come through their doors but also to extend the invitation beyond, to invite new audiences into art galleries and make them feel welcome, comfortable and engaged.

Through understanding visitor needs as laid out in the work of Falk and Rand, it is possible to address the diversity of audience identity, motivations, expectations and desired delivery styles. Coupled with case studies from books such as Interpreting the Art Museum and The Art of Relevance, I start to draw together a picture of how audience-centric art interpretation could be put into practice. The design of my research aims to understand the local context by exploring interpretive planning and practice in Wellington public art galleries.

\section{Research approach}

To address my dissertation topic, I take a qualitative case study approach to illuminate the general by exploring specific examples. Using three Wellington public art galleries - Pātaka Art + Museum, The Dowse Art Museum and the Adam Art Gallery - I explore current local interpretive practice. I explore in-depth the interpretation strategies, staff decision making and programming at galleries that serve different communities, vary in physical, organisational and staffing size, and have different programming focuses within the realm of contemporary art. The differences between case studies offer opportunities for interesting comparisons and may represent, to some extent, the diversity of public art galleries and interpretation strategies employed in the sector in New Zealand. 
The qualitative case study approach allows me to explore relationships and processes, not only explaining what goes on, but why those things occur. ${ }^{34}$ Exhibition-making and interpretation are complex processes involving many people, ideas and ideologies, making case studies advantageous in providing a holistic view. The potential disadvantages of this approach include a focus on process rather than outcomes and the challenge of producing generalisable findings. ${ }^{35}$ Due to the scale of this project, a selective range of qualitative data is sufficient to understand current interpretive practice. However, further research into visitor experiences would be valuable. Employing a multiple-case study approach increases the generalisability of the findings, so that similarities and differences can be drawn across a range of contexts. ${ }^{36}$

\section{Methodology}

The primary data collection method for this study was qualitative interviews with gallery staff. The secondary research questions below helped inform the approach to, and the focus of, the data collection.

- What is the current state of interpretive practice in small-medium public art galleries in Wellington?

- Are audience needs and motivations currently being considered and/or sample audience groups being consulted as part of the exhibition development process?

- What are the reasons for providing interpretation?

- What training and development opportunities are there to support interpretation practice?

I used a semi-structured interview technique, which allowed interviewees to guide the order and depth of the topics covered. ${ }^{37}$ This open-ended approach encouraged interviewees to speak more broadly about art interpretation, the way they see their roles and the purpose of their organisations. Using an iterative, grounded theory approach, I was able to learn from the experience of each interview and adapt the questions as appropriate (see appendix for list of interview questions). While there are difficulties in drawing comparisons between data sets using semi-structured interviews, the depth of information provided is very useful, valuable and worth pursuing.

34 Martyn Denscombe, The Good Research Guide: For Small-Scale Social Research Projects (McGraw-Hill Education (UK), 2014), 55 .

35 Denscombe, 64.

36 Robert Yin, 'How to Do Better Case Studies: (With Illustrations from 20 Exemplary Case Studies)', in The SAGE Handbook of Applied Social Research Methods, by Leonard Bickman and Debra Rog (Thousand Oaks California, United States: SAGE Publications, 2009), 260.

37 Denscombe, The Good Research Guide, 186. 
From each of the three case study galleries, I interviewed two staff members - the director and a senior curator. Due to the small, tight-knit nature of New Zealand's art gallery community, naming the interview participants was appropriate. There is little to no risk of interviewees experiencing any adverse effects from being identified in the study, and as the galleries are named, the individuals could be easily identified in any case. This choice was made explicit in the consent forms. As the research aimed to capture a snapshot of current practice, with the intention of developing a framework for supporting professional practice, participants were happy to take part and be named.

I had originally intended to carry out a focus group with front of house staff from across the case study galleries. However, organising a group of busy and diverse staff members proved difficult. Due to time constraints and weighing up the relevance to answering my research question, I decided that the data gathered from interviews was sufficient. I still feel that front of house staff have a lot to offer and further research would be useful in this area.

\section{Chapter outline}

Chapter one describes the research context, including audience-centric interpretation examples from international institutions, digital interpretation principles, critical reflection as professional practice and gives background to the research and resources available for interpretation practitioners in New Zealand. This chapter also describes the case study organisations and interviewees. Chapter two outlines the findings from the interviews, covering understandings of interpretation, audiences, processes of development, pressures, limitations and why interpretation is necessary. The third chapter provides analysis of the findings, discusses observations and reflects on how audience-centric interpretation might be put into practice. The conclusion discusses how my research contributes to local knowledge of art interpretation practice. I also recommend several principles and strategies for audience-centric art interpretation in small-medium public art galleries. 




\section{Chapter One}

Setting the Scene 
This chapter describes the context within which my research is situated and gives background to the case study galleries in relation to my over-arching research question:

\section{How might small-medium New Zealand public art galleries enhance the diversity and accessibility of visitor experiences through a more audience-centric approach to art interpretation?}

I begin by describing international examples of innovative audience-centric art interpretation, explore digital interpretation principles and critical reflection on interpretation practice as benchmarks against which to evaluate local gallery practice. Focusing on the New Zealand context, I describe the resources and research about and available to local galleries before giving brief histories of the case study galleries and the interview participants from each.

\section{Research context}

\section{International examples of audience-centric interpretation}

The volume, Interpreting the Art Museum (2015), edited by Graeme Farnell is a collection of essays and case studies looking at the practice of interpretation in art museums. In the foreword, Judith Koke describes interpretive planning as a young profession, only just beginning to build a shared body of knowledge, language and practice. It is through building shared experience, research and vocabulary that the profession will be able to develop the strong evidence necessary to supporting true institutional change. ${ }^{1}$ Farnell hopes that the book will encourage 'sensitive and effective' interpretation but identifies a range of particularly challenging issues faced by art museums:

- A concern not to spoil the direct, often sensitive, relationship between the viewer and the work of art;

- The perceived difficulty of tackling sometimes particularly esoteric, complex or controversial themes;

- An unwillingness to offer one single interpretation or meaning for a work;

- The view that a work of art should be allowed to "speak for itself" and not be interpreted. ${ }^{2}$

These challenges echo those identified by Latimer and Wright and touch on themes throughout the texts on art interpretation. By bringing together case studies of innovative interpretation

1 Judith Koke, 'Foreword', in Interpreting the Art Museum, ed. Graeme Farnell (Edinburgh: Museums Etc., 2015), 11.

2 Graeme Farnell, ed., Interpreting the Art Museum (Edinburgh: Museums Etc., 2015), 13. 
coupled with evaluation and critical discussion, Farnell aims to stimulate both thought and action in moving the field of art interpretation forward.

Case studies and essays included in Interpreting the Art Museum address the different engaging and innovative ways that art museums have interpreted art. The first section, 'What to interpret', includes examples of interpretive planning with audiences, framing strategies and visitor-centred philosophies and practices. While I do not have space to discuss each chapter, I have chosen a representative example from each section to discuss. Chapter eight: "Building meaningful interpretation around unsettling contemporary art" deals with how the Portland Art Museum's education team encouraged personal reflection and physical engagement with a challenging and complex artwork, The Enclave (2013). Respecting that not all visitors have the capacity or want to engage in the same way, they offered a range of interpretive options. These strategies included:

- An in-gallery interpretation space designed for visitor reflection and response

This space was designed to empower self-guiding visitors to work through their reactions and responses to the work individually. Deliberately left silent, devoid of the museum's point of view or any curatorial voice, it instead 'provided a comfortable space for visitors to have and share their own perspectives.'

- Printed postcards inviting visitor written responses

One side printed with a photograph from the exhibition, the other displayed with interpretive prompts 'I saw... I heard... I felt', these were placed within the reflection space. Visitors were encouraged to read others' responses and leave their own.

- A Tumblr site on which the museum regularly posted visitor responses to The Enclave

A sign within the space invited visitors to read others' responses via their Tumblr site, allowing for engagement within and beyond the gallery - encouraging ongoing community commentary about the exhibition. ${ }^{3}$

- The gallery also partnered with a locally based non-profit organisation (Mercy Corps) who had experience with the work's subject matter and helped the gallery run workshops for both staff and school groups.

3 Kristin Bayans, Mike Murawski, and Phillipa Pitts, 'Building Meaningful Interpretation Around Unsettling Contemporary Art', in Interpreting the Art Museum (Edinburgh: Museums Etc., 2015), 164-167. 
The value of using a variety of interpretive strategies for such challenging, immersive and socially relevant works of art can be seen in the quality of visitor reflection and sharing visible in the visitor comments. Meaningful experiences were fostered through personal reflection and opportunities for extended learning helped 'anchor the museum as a museum of its place, not just a museum in its place'.

The second section of the collection deals with 'how to interpret' and includes examples of learning initiatives, emotional mapping, kinaesthetic experiences, late events and different styles and modes of delivery. Chapter seventeen: "A Spectrum of Experience: Creating Interpretive Programs for Adults" discusses the re-design of Cleveland Museum of Art's interpretive programmes after visitor surveys revealed their current offerings were only serving a limited audience (i.e. white, female, educated and between 50-75). For staff, this lack of diversity 'highlighted the failure of adult programming to support the museum's mission: to bring the pleasure and meaning of art to the broadest possible audience'. 5 The museum developed a new planning model: a spectrum of programme types offering more opportunities to engage with the museum through a broader range of experiences. Efforts fell into three broad categories:

- Establishing more formats and inviting a wider array of voices to offer perspectives.

- Connecting to personal interests beyond art and art history.

- Promoting creative expression inspired by the collections.

Introducing thematic programming, art-making, performances in galleries, demonstrations, tours and scavenger hunts encouraged curiosity and fun, while still being informative and attracting new audiences to engage meaningfully with the art. The most important take-away message from this study, however, is the importance of visitor research in understanding audience make-up (to address diversity), as well as identifying visitor motivations and preferences (to inform saturation, content and programme types). Even if galleries do not undertake formal visitor research, anecdotal information observed at events will give staff an indication of successes and areas for improvement.

\section{Digital interpretation principles}

It is impossible to ignore the power and reach of digital interpretation for museums and galleries. From institutional websites to online collections databases, these resources set up

4 Bayans, Murawski, and Pitts, 175.

5 Bethany Corriveau, 'A Spectrum of Experience: Creating Interpretive Programs for Adults', in Interpreting the Art Museum (Edinburgh: Museums Etc., 2015), 322. 
audiences' expectations and enhance their on-site experiences or offer a connection with the museum or gallery from afar. Though most small-medium galleries have websites informing potential visitors of basic information such as opening hours, location, events and exhibitions, they are not necessarily used to their full potential for interpretation. Digital publishing in the form of a blog is a relatively easy way to disseminate audience-friendly information about collection items and/or exhibitions to inform or prime audiences for the museum's offerings.

Kris Wetterlund, museum educator and editor of Museum-Ed (www.museum-ed.org), identifies information-sharing platforms such as blogs and social media as allowing more people to join in the creation and distribution of knowledge. Wetterlund describes how 'open access to collections online and social media are allowing everyone to blog, tweet, talk, and otherwise publicly ponder the meaning of a museum's collection,' and expounds the belief that 'community knowledge generated by social media doesn't take authority away from the museum, but rather adds to it'. ${ }^{6}$ Digital communication tools allow galleries to extend the conversation beyond what is in their exhibitions and can empower audiences to connect and create their own meanings. Social media platforms can also allow for feedback and the ability for institutions to talk directly with their audiences.

Large museums and galleries around the world are experimenting with digital interactive technologies to enhance engagement within their institution's walls. These can include touch screen devices for viewing extra information about collections, digital labels and audio-visual material such as recorded interviews, demonstrations and explanations of various objects, processes or personalities. The Cooper Hewitt, Smithsonian Design Museum offers one such example of totally integrated digital interpretation. In 2012, the institution began an entire overhaul of its exhibitions and digital platforms, with the development team establishing a series of technology principles to help shape the galleries and experience:

- Give visitors explicit permission to play.

- Make interactive experiences social and multi-player, allow people to learn by watching others.

- Ensure a 'look up' experience. (i.e. encourage people to interact with their physical surroundings, not just their digital platform).

- Be ubiquitous, a "default" operating mode for the institution.

6 Kris Wetterlund, 'The Voice of Authority', Journal of Museum Education 37, no. 2 (1 June 2012): 89. 
- Work in conjunction with the web, and offer a "persistence of visit." (before and after visit interaction, not just on site). ${ }^{7}$

While small-medium galleries do not have the budget or expertise to create a platform on the same scale as the Cooper Hewitt model, these design principles put audiences first. Technology or digital platforms do not need to be overly high tech to engage audiences and having digital interpretation just for the sake of having a whizzy gadget is not going to create a meaningful experience for audiences. The Cooper Hewitt 'Pen' allowed for system-wide engagement focused on individual experience, fostering design understanding and creativity - interpretation at a much deeper level than knowledge transfer, instead fostering understanding through doing.

If museums and galleries are going to employ digital interpretation, their success will rest on the principles behind the design of the technology. As the Cooper Hewitt Pen demonstrates, audience-centric design is essential in creating a meaningful experience for audiences. The institution understood that 'the pen can only be seen as successful insofar as it enables the museum and its visitors to do more with our collection'. ${ }^{8}$ This is what all cultural institutions should aim to do with whatever level of digital interpretation they choose to employ - connecting audiences with art is the aim.

\section{Critical reflection on interpretation practice}

Cheryl Meszaros's work on understanding interpretive practice provides a useful model for how galleries might become more self-conscious about how and why interpretation is done. Working with gallery staff, Meszaros explores the history and practices of different interpretation styles. She points out that traditional museums constitute their interpretive authority with label texts offering 'instruction on the nature of the object or artefact, its context, its significance, how it is to be understood, or what it means'. ${ }^{9}$ Meszaros fosters self-conscious critically engaged interpretive practice by acknowledging and making accessible to the public different interpretive repertoires. In her seminars, she gets staff to understand and articulate the interpretive practices the museum may have unknowingly championed. Using guiding questions, such as "How do you figure things out? If you encounter an unfamiliar object, how do you understand it?", she helps

7 Sebastian Chan and Aaron Cope, 'Strategies against Architecture: Interactive Media and Transformative Technology at the Cooper Hewitt, Smithsonian Design Museum', Curator: The Museum Journal 58, no. 3 (1 July 2015): 355-57.

8 Chan and Cope, 363.

9 Meszaros, 'Interpretation and the Art Museum: Between the Familiar and the Unfamiliar', 37. 
staff understand their audiences' needs and processes for interpretation. ${ }^{10}$ She encourages a form of ethical interpretation where the public is made aware of interpretive constructions, encouraging them to be critical. Audiences' abilities to draw connections between their lives and the wider processes of the world around them, Meszaros believes, will ultimately encourage transformative moments.

Museum studies scholar, Janet Marstine, deals with the complexity and nuance of the relationships between galleries, artists and the public. In her recent book, Critical Practice: Artists, Museums, Ethics (2017), Marstine takes a cross disciplinary approach to understanding the history and blurred boundaries between institutional critique and socially-engaged art practice. She proposes that museum and gallery practitioners themselves need to develop a 'critical practice' in which they operate as facilitators of organisational change, increased public agency and shared authority. This approach requires galleries to be fully self-conscious and to actively plan for their future direction, creating sustainable relationships with their communities, deciding on an interpretive direction and explicitly promoting reflexive thinking among their staff.

Understanding the work of museums and galleries as a form of practice worthy of study in its own right is a position championed by local scholar, Conal McCarthy. In his chapter, 'Theorising Museum Practice through Practice Theory' (2016), McCarthy calls for a closer relationship between theory and practice in order to promote critical reflection and advancement in the work of museums and galleries. He quotes Silverman and O'Neil, saying the problem is that "“our demanding daily schedules leaves little time for deep, critical and sustained discussion and analysis of theory' and therefore a 'deeper and more complex understanding of the museum experience' ... They contend that 'too many museums remain uncommitted to the development of a deeper understanding of the field as a cornerstone of practice"'. ${ }^{11}$ McCarthy describes this shortfall in museum studies as lacking 'the kind of wide-ranging and detailed empirical studies of professional practice in museums that are found in practice-based enquiry in hospitals, schools and other professional settings' ${ }^{12}$ Scholarship in partnership with practitioners is necessary to understand the relationships, ethics and cultural practices at play. The hope is that Lyn Teather's idea of a

10 Meszaros, 48.

11 Conal McCarthy, 'Theorising Museum Practice through Practice Theory: Museum Studies as Intercultural Practice', in The Routledge International Handbook of Intercultural Arts Research, by Pamela Burnard, Elizabeth Mackinlay, and Kimberly Powell (London, UNITED KINGDOM: Taylor \& Francis Group, 2016), 25.

12 McCarthy, 30. 
"Critical Reflexive Museum Practice" is realised to "empower the professional through reflexive learning and professional development'. ${ }^{13}$

\section{New Zealand research and resources}

David Mason and Conal McCarthy's article, “The feeling of exclusion: young people's perceptions of art galleries" (2006), gives a helpful overview of visitor inclusion and exclusion in New Zealand art galleries, especially psychological barriers and identity construction. Their research, which focuses on young people's gallery non-visitation and perceptions of the Auckland Art Gallery, highlights the difficulties in getting audiences across the threshold of an institution even before engaging them with art interpretation. Also, as there is so little qualitative research about gallery visitation within a New Zealand context, this study is important for me to understand and build on. I hope that my research will also complement previous Museum and Heritage Studies theses which have covered aspects of interpretation and accessibility such as Riah King-Wall's Path to Accessibility: The current state of disability access in Aotearoa New Zealand museums (2016) and Claire Baker's Good intentions: A case study of social inclusion and its evaluation in local public art galleries (2014).

New Zealand has a number of national bodies, including Creative New Zealand, Museums Aotearoa and National Services Te Paerangi (NSTP), that set standards, principles and guidelines for the museum and gallery sector. These organisations provide training, resources, networking and national standards of ethics and practice that are particularly important for local galleries. NSTP produce information brochures about different aspects of museum and gallery practice including such topics as: 'Know Your Visitors', 'Writing Effective Interpretive Text', and 'Exhibition Display Techniques'. ${ }^{14}$ They also offer a wide range of practical and strategic programmes in partnership with museums, galleries and iwi aimed at strengthening the museum sector in New Zealand.

Museums Aotearoa is the independent professional association for New Zealand's museums and galleries, and people working in the sector. They advocate on behalf of their members and the sector, nurture excellence in professional practice and extend manaakitanga towards members, all

13 McCarthy, 26; J. Lynne Teather, 'Museum Studies: Reflecting on Reflective Practice', Museum Management and Curatorship 10, no. 4 (1991): 403-417; Lynne Teather and J. Carter, 'Critical Museology Now: Theory/Practice/Theory', Muse (Nov./Dec.), 2009, 22-33.

14 National Services Te Pairangi, 'Resources and Reports', Museum of New Zealand Te Papa Tongarewa, Wellington, NZ, 9 February 2016, https://www.tepapa.govt.nz/learn/for-museums-and-galleries/howguides/resources-and-reports. 
underpinned by a commitment to the principles of Te Tiriti o Waitangi. ${ }^{15}$ Of note is their Code of Ethics which governs how museums and galleries in New Zealand are expected to behave. Specifically relating to interpretation, clause $2.1 \mathrm{~b}$ states that museum and art gallery managers will ensure 'accurate, relevant and accessible interpretative information is available to visitors, taking reasonable account of those with various impairments, in a variety of appropriate formats within and accompanying exhibitions and displays'. ${ }^{16}$ The code also stipulates that museums and galleries ensure active engagement with tangata whenua and other relevant communities in the development of exhibitions, displays, education and public programmes and that there is a duty to make collections accessible to audiences across all relevant platforms. The explicit public service mission of museums and galleries as public institutions stated in this Code of Ethics is of particular relevance to my research. Museums Aotearoa also administers a yearly national visitor survey which creates a comprehensive database of visitor demographic information from across the country. The aggregated data is collated into an infographic poster for each year, as in the FebruaryMarch $2017^{17}$ poster below:

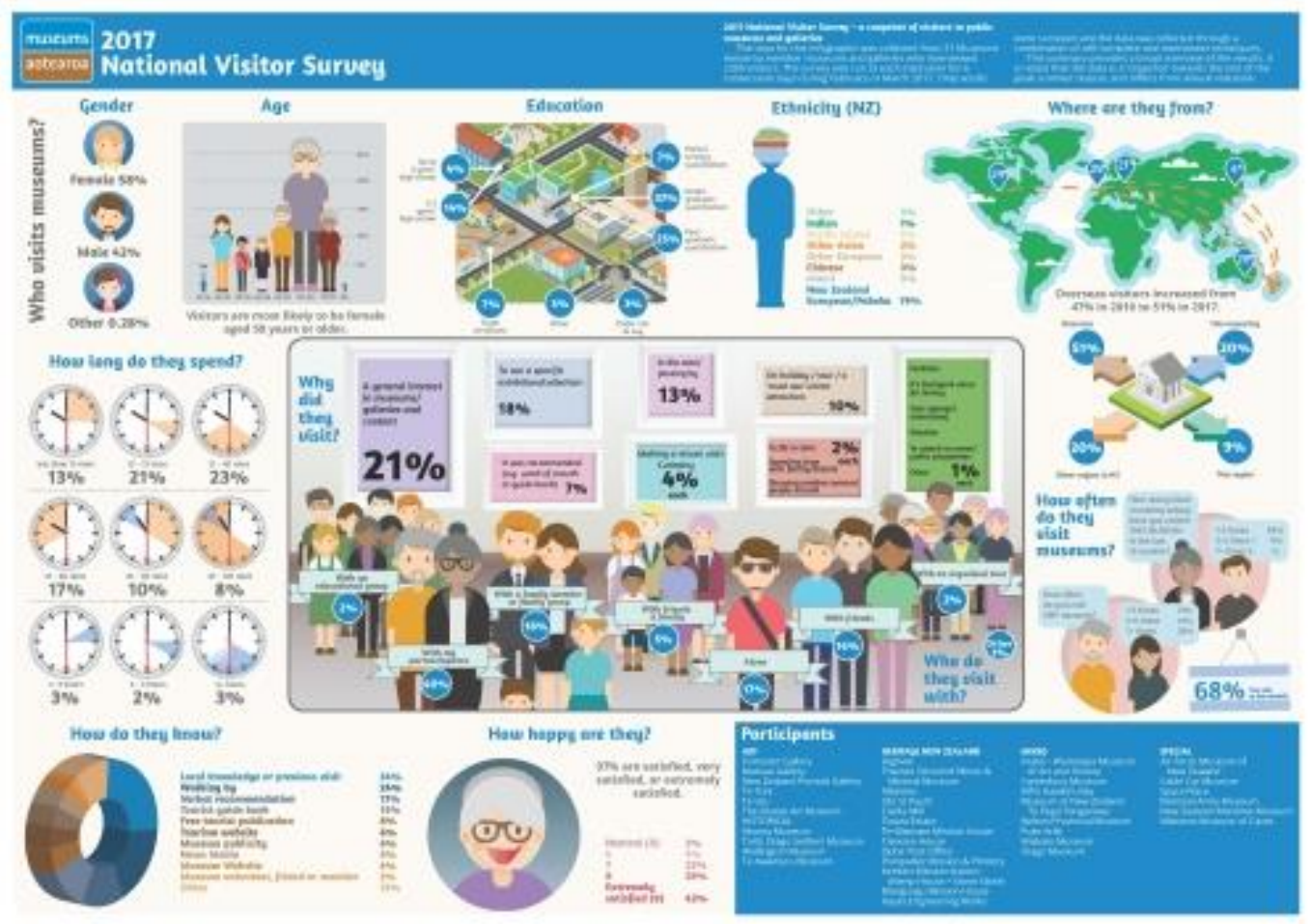

15 Museums Aotearoa, 'Museums Aotearoa', Museums Aotearoa, accessed 9 March 2018, http://www.museumsaotearoa.org.nz/.

16 'Museums Aotearoa Code of Ethics 2014', accessed 9 March 2018, http://www.museumsaotearoa.org.nz/sites/default/files/ma_code_of_ethics_br_2014_v5_web_0.pdf.

17 Museums Aotearoa, 'Research', Museums Aotearoa, accessed 21 March 2018, http://www.museumsaotearoa.org.nz/research. 
Within the wider arts, culture and leisure sector, Creative New Zealand is a crown entity governed by the Arts Council that encourages, promotes and supports New Zealand arts for the benefit of all New Zealanders through funding, capability building and advocacy. ${ }^{18}$ Creative New Zealand carries out and publishes research on attitudes, attendance and participation in the arts every three years, enabling a better understanding of the culture market over time. In 2011, they introduced a new way of understanding audiences through segmentation based on the underlying values and needs of audiences. Working with Morris Hargreaves McIntyre (MHM) who developed the 'Culture Segments' system, they used data gathered from Audience Atlas New Zealand to offer insight into audiences of the cultural sector. ${ }^{19}$ Culture Segments is an international standard segmentation system for arts, culture and heritage organisations providing 'compelling, shared language and deep insight to understand audiences' based on people's 'deep-seated cultural values and their beliefs about the role that culture plays in their lives. ${ }^{, 20}$ The eight segments in the system are: enrichment, entertainment, expression, perspective, stimulation, affirmation, release and essence. Such segmentation is used by larger organisations such as Te Papa but could be equally useful and is freely available to smaller organisations.

\section{Background to case studies}

For my research, I chose three small-medium public art galleries in the Wellington region as case studies: Pātaka Art + Museum, The Dowse Art Museum and the Adam Art Gallery. Before discussing these organisations and their staff in detail, it is useful to understand their context within the ecosystem of galleries in the region. Due to its socio-geography, Wellington has many wellestablished galleries within close proximity. These include the national art gallery at Museum of New Zealand Te Papa Tongarewa, the municipal City Gallery Wellington, smaller institutions such as the New Zealand Portrait Gallery, Enjoy Public Art Gallery and the community art gallery Toi Poneke, the artist run spaces Meanwhile and Play Station, and dealer galleries such as Peter McLeavey, Page Blackie and Bartley + Company. These institutions represent a wide range of types, sizes, purposes and offerings. I was interested in studying the institutions towards the centre

18 Creative New Zealand, 'About Creative NZ', accessed 9 March 2018, http://www.creativenz.govt.nz/aboutcreative-new-zealand.

19 Creative New Zealand, 'Research and Reports', accessed 9 March 2018, http://www.creativenz.govt.nz/development-and-resources/research-and-reports.

20 Morris Hargreaves McIntyre, 'Culture Segments', accessed 9 March 2018, https://mhminsight.com/articles/culture-segments-1179. 
of this spectrum - the small-medium public art galleries - as they are both under-researched and represent a common form of gallery around the country.

\section{Pātaka Art + Museum}

Pātaka Art + Museum opened on Parumoana Street in September 1998 and is the municipal gallery of Porirua City. Located in the complex, Te Marae o Te Umu Kai o Hau, with the Porirua City Library, a café, community meeting rooms and a Japanese garden, Pātaka is the cultural hub of Porirua. Pātaka has developed a strong focus on exhibiting Māori and Pacific arts, as well as contemporary New Zealand, Asian and international arts and culture. There are five main galleries, typically showing over 14 major exhibitions each year. The Blue Pacific Gallery shows artwork for sale by contemporary New Zealand artists and the Bottle Creek Gallery is a community gallery where local creativity is showcased. Proposals for Bottle Creek exhibitions are reserved for artists, arts groups and collectives who reflect or engage with the communities of Porirua. ${ }^{21}$

\section{Interviewees}

Reuben Friend, Director of Pātaka, has a Masters in Māori Visual Arts from Massey University and has held positions such as Director of Te Upoko Pacific Art Consultancy, Exhibitions Officer at Logan Art Gallery and Curator of Māori and Pacific Arts at City Gallery Wellington, before taking up his current position in 2015.

Mark Hutchins-Pond, Contemporary Art Curator at Pātaka, has a Master of Fine Arts from Elam School of Fine Arts, University of Auckland. Beginning his career as a Prints and Drawings Collection Intern at Te Papa, Hutchins-Pond worked as a private art dealer before taking up his current position in 2013.

\section{The Dowse Art Museum}

The Dowse Art Museum was opened on Liangs Road in 1971 as the municipal art gallery of Hutt City. The gallery was named for Mayor Percy and Mayoress Mary Dowse who were instrumental in having the gallery founded, although sadly neither of them lived to see the gallery opened. The gallery is primarily funded by the Hutt City Council, is supported by The Friends of the Dowse and its collection began with a gift of 70 paintings by The Hutt Art Society. The gallery has a focus on craft and decorative arts as well as showing a diverse programme of contemporary art. As a regional city gallery, the aim of the organisation is to 'enable people to freely access arts and cultural facilities that enrich, inspire and offer a range of lifelong learning opportunities. The

21 Pātaka Art + Museum, 'History', Pātaka, accessed 9 March 2018, https://www.pataka.org.nz/about-us/galleryhistory/. 
museum acts as a focal point for the community, enhances cultural life and diversity, and promotes civic pride and community values. ${ }^{22}$

\section{Interviewees}

Courtney Johnston, Director of the Dowse, gained her Master of Art History from Victoria University of Wellington, worked as Communications Advisor, then Web Editor and Web Manager at the National Library of New Zealand and General Manager at Boost New Media before taking up her current position leading the Dowse and Petone Settlers Museum in 2012. Johnston also holds board positions on The Pantograph Punch, Arts Wellington and Museums Aotearoa and is a weekly arts correspondent for Radio New Zealand.

Melanie Oliver, Senior Curator at the Dowse, completed postgraduate study at Victoria University of Wellington, worked as Gallery Manager at Enjoy Public Art Gallery, Assistant Curator at the Govett-Brewster and Artspace Sydney, Learning Programme Specialist at National Library, and Director of The Physics Room before taking up her current role in 2016.

\section{Adam Art Gallery}

The Adam Art Gallery Te Pātaka Toi is the campus gallery of Victoria University of Wellington. The building, opened in September 1999, was designed by Ian Athfield to fit between three university buildings: Old Kirk, Hunter and the Student Union, and was made possible by the patronage of Denis and Verna Adam. The gallery manages the Victoria University of Wellington Art Collection which was initiated by university staff in 1947, who voted to set aside funds to acquire original works of New Zealand art. Now numbering more than 600 works, it is a nationally significant collection of modern and contemporary New Zealand art and is displayed in the public spaces of the university. The gallery itself has developed a reputation as a platform for 'critical thinking across media, disciplines, cultures and contexts. Using art and its presentation as a tool of analysis, it contributes to the production of new knowledge and creates opportunities for learning, for the benefit of staff, students and the wider community. ${ }^{23}$

\section{Interviewees}

Christina Barton, Director of the Adam Art Gallery, completed her Master of Art History at the University of Auckland and has since worked as Assistant Curator at Auckland Art Gallery and Curator of Contemporary New Zealand Art at Museum of New Zealand Te Papa Tongarewa.

22 The Dowse Art Museum, 'History', accessed 9 March 2018, http://www.dowse.org.nz/about/history.

23 Adam Art Gallery, 'Vision \& Mission', accessed 9 March 2018, http://www.adamartgallery.org.nz/aboutexhibitions/vision-and-mission-statement/. 
More recently, she taught Art History at Victoria University of Wellington. Barton was appointed Director of the Adam Art Gallery in 2007 and is a prominent art historian, writer and commentator on contemporary New Zealand art.

Stephen Cleland, Curator at the Adam Art Gallery, has a BA, BFA and Postgraduate Diploma of Fine Arts (by curatorial portfolio) from the University of Auckland. Cleland was a co-founder and curator of Window Project at the University of Auckland, Exhibitions Manager and Curatorial Assistant, then Curator at Te Tuhi Centre for the Arts, Director at The Physics Room, Acting Contemporary Art Curator at Auckland Art Gallery and he then took up his current position at the Adam in 2015.

\section{Conclusion}

New Zealand public art galleries can learn a lot from audience-centric interpretation approaches adopted overseas and there is valuable literature to draw upon. Furnell's volume, Interpreting the Art Museum, offers compelling examples of galleries that have put audiences at the heart of what they do, creating diverse entry points and purposeful content. The authors advocate respecting and encouraging individual meaning-making, connecting the subject matter with audiences' lives and provoking deep thought - all areas that enhance diversity of experience and accessibility for audiences.

For local context, I have described the resources and research available to New Zealand galleries covering gallery visiting, audience makeup and interpretation guidelines. The Museums Aotearoa Code of Ethics requires galleries to create accurate, accessible and relevant interpretation and to actively engage with relevant communities in the development of exhibitions. Through interviewing staff at my chosen case study institutions, I explore understandings of the philosophies and concepts of interpretation and delve into current interpretive planning and practice. The next chapter describes the findings from these interviews. 



\section{Chapter Two}

\section{Interpretation in Practice}


The interviews with practitioners from Pātaka, the Dowse and the Adam Art Galleries have illuminated some of the practices, philosophies, opportunities and frustrations for art interpretation in our local context. Having carried out the interviews using an iterative, groundedtheory approach, I was able to let the interviewees guide the depth and direction of enquiry into their understandings and practices of interpretation. I transcribed the interviews in their entirety, using the process to familiarise myself with and draw out initial trends and observations across the data sets. I then read, re-read and annotated the transcripts, comparing the contents and focusing on the similarities and differences between the approaches of each case study institution and practitioner. The contents of this chapter describe my findings, covering understandings of interpretation, understanding of audiences, the development of interpretation, interpretation planning and strategies, pressures and limitations and finally 'why interpret?' - an exploration of the underlying philosophies for providing interpretation for art.

\section{Understandings of interpretation}

Interpretation in art galleries includes more than just wall labels and, in fact, incorporates all forms of communication produced by galleries. While conversations with practitioners tended to focus on the content of wall labels as the prime example of interpretation, they understand interpretation to be much wider than that. From advertising and social media, to public programmes and the design of exhibitions, to the long form writing produced in exhibition catalogues - each of these forms communicate information about the exhibitions to audiences.

Identified in the interviews, the range of types of interpretation are broken down here into three sections: those that are a precursor to visiting the gallery; the in-gallery interpretation; and the longer view of interpretation.

\section{Pre-visit interpretation}

- Advertising material - brochures, posters, website blurbs

- Brand of museum/gallery - reputation, focus, type

- Press/media releases

- Social media and email - invitations

In-gallery interpretation

- Wall text/labels (language, size, design, location)

- Handouts/information that people can take away

- Face to face interpretation (FOH staff, education programmes, curator talks) 
- Public programmes (talks, discussion panels, tours, screenings, performances, openings, conferences, makers' events, etc.)

- Layout and design of exhibition (orientation, mood, juxtaposition)

- Zines/artist published material

\section{Longer-term interpretation}

- Reviews or articles in art magazines and newspapers or on art websites/blogs

- Catalogues/publications

- Choice of artists/exhibitions over a 1-5 year period - the programming of exhibitions

There is a huge variety of types of interpretation produced by each of the galleries. Mark Hutchins-Pond summed up Pātaka's interpretation into broad categories.

We have three or four main types, the most accessible form of interpretation is what goes in our seasonal brochures which is very stripped down, simple, a paragraph about each show. That's usually also on our website but then we do have extrapolations on the website for people who want more information. Level two would probably also be the signage panels that we have in the gallery, so level three would then be any publications that we would choose to produce. And beside those three main forms, there's also educational interpretation which is pitched for children. ${ }^{1}$

Mark goes on to explain that there are different levels of interpretation for different types of visitors and visitor needs.

The different levels or grades of interpretation are for different audiences, there's the interpretation that is designed to engage children or school groups, [...] then when the people are in the exhibition themselves, you want something that's pitched to visitors who are in the space who are looking at the work. And then interpretation that is in publications is more about putting things in more of an academic sector specific audience.

Courtney Johnston explains these different levels at the Dowse, but also includes forms of interpretation that are semi or completely outside the gallery's control.

There's face to face interpretation, whether that's you're going around with a curator or you're going on a tour or you're working with our educators, that happens in real time. That's the highest bandwidth because that's where a person gets an opportunity to ask live questions and also for the person who's doing the interpreting to pick up on cues and to tailor to what's going

1 Mark Hutchins-Pond, Pātaka Art + Museum - Curator, 5 October 2017. All following quotes in this chapter are from research interviews and can be found listed by interviewee in the bibliography. 
on. I guess with some of our shows, especially in our education gallery upstairs, we do think about parents or caregivers being the interpreters so often the interpretation in that particular space is written with a mind towards adults who are looking to engage with kids [... Then] there is a layer of interpretation that is semi-in our control and semi-out of our control which is publicity and marketing and media promotion of an exhibition. There's another layer which is fully out of our control which is critical responses and receptions. And then there's the layer that we write and construct and put out there and typically that takes the form of wall labels. In the past and as is appropriate, we've sometimes done big publications, small publications, podcasts, possibly video (I'm not sure), and I'd put social media into that band of promotional activities.

The different levels of interpretation identified by practitioners give gallery visitors options about how they interact and engage with the art and exhibitions on show. Christina Barton made an interesting observation about the link between art and language.

... when you think about art, it is completely surrounded and immersed in language both within an artwork in terms of the artist's signature, the title of the work, the inscriptions, the cataloguing, the intrinsic words that make it available to be talked about and then there's the ways in which we use art and present art and think about art which are all couched in language [...] I believe that art is embedded in a whole variety of different layers of words. I also think that to unlock the language that art itself speaks is something that is learnt, has a history and that there is a vocabulary to do that.

Especially operating in a university context, scholarship and extended written interpretation have a strong emphasis at the Adam Art Gallery. Stephen Cleland comments that "we place quite a lot of importance on framing our exhibitions in long and short form writing." He also talks about embracing specialist language.

...we are trying to pitch to the level that an art history student or art curious person on campus could understand and get a greater depth out of the artwork. So, in that sense I've always believed that universities are quite good places for art galleries to exist because we don't quite have the same pressure that a public institution like Te Papa or City Gallery might have to simplify a description of a work to a degree that any lay person can understand it. Obviously, hopefully people still can but there might just be a little bit more work here because we're trying to also embrace those depths that artworks have in such a way that every discipline on campus from the sciences to the arts they have their own specialist language, so I think that we can embrace that to some degree here in order to achieve a depth of understanding that we're trying to promote. 
As well as using language, there are other ways of doing interpretation that are more subtle and rely on exhibition design and juxtaposition of works. Melanie Oliver gave the example of her show, Emma Fitts: From Pressure to Vibration - The Event of a Thread (25 March-2 July 2017), at the Dowse.

I'm also interested in the idea that [interpretation] doesn't necessarily even have to be about reading. There are other ways you can bring it in, so for the exhibition I did with Emma Fitts earlier this year we provided quite a lot of textual information, but I also provided a lot of other work from the collection. Emma made six new works and then I brought out twenty odd items from our collection that were meant to offer other ways of thinking about her work. Some was raranga - Māori weaving, some was little samples of hand loom weaving, some were woven tapestries, or some were large scale architectural pieces, so trying to encourage people to think about how does textile history think about modernism or think about architecture, but not actually through text but through other works. So, I think you can also use other kinds of things like wall colours, all sorts of other things can be seen to be part of the interpretation of the work.

Practitioners also talked about having different spaces with different purposes, mostly regarding child or family friendly spaces - both Pātaka and the Dowse have spaces with a specific family focus. Melanie talks about how she works quite differently when curating for the family lounge at the Dowse.

I work a lot with our education team [...] I ask them what will meet the curriculum, what will interest teachers and students, what they can use in terms of activities to work with a wide range of different age groups and then build something that hopefully makes sense as a small exhibition as well.

Courtney also comments that visitors' motivations influence the tone of the interpretation.

We do think about parents or caregivers being the interpreters $[\ldots]$ so giving them something that they can use or riff off because parents in particular when they come to the gallery are in that sort of facilitator role, where they're not necessarily there for their own pleasure, they're there because they want to create an experience for the people that they are with.

At Pātaka, Mark describes their children's gallery - the Tuatara Gallery.

[The Tuatara Gallery] has interactive exhibitions and elements within the space that parents can use to engage their children. The idea is that [...] what's in the children's space relates to what is on in the main exhibition space but is pitched at a different level.

Pātaka also has a community gallery which has a different focus and different level of interpretation. Reuben Friend talks about how this space differs from the main gallery spaces. 
...for a community gallery like we have, it's community art, it's pretty simple stuff, it's within the notion of art that people understand, you know, landscape paintings, sculptures, vases, pottery and we can do quite minimal text with that. [...] it's stuff that people know, and it doesn't feel high end, doesn't feel like you need to be immersed in art, contemporary art theory to get it. So, people have a sense of ownership, we can go there, we get it, we like that. Whereas with the other spaces it's more difficult so you have to help them and encourage them.

\section{Understanding of audiences}

I was curious to find out how well practitioners knew their audiences, whether their understanding was from anecdotal observation or more rigorous visitor research and whether they had particular audiences in mind when creating interpretation.

Stephen admitted to only having an anecdotal understanding of who visits the Adam Art Gallery, mostly from openings and public programmes.

I don't think we have done any exhaustive surveys in some time. I don't know if our information is super accurate around who our audience is. Naturally I'm very engaged in the art world so I'm very aware of the makeup of people who attend our openings. [...] We have an extensive public programme so we have a range of talks, screenings, performance events, various things that the gallery hosts so I'm present at all those events. So, you get to know that audience who's engaged at a level that wants to come along to a talk by an art historian on a Saturday afternoon. But then on a daily and weekly basis we also have an extensive group of volunteers who actually mind the gallery [...] But the trade-off is that you don't necessarily know all those intimate details about who's visited on a daily or weekly basis. So, in that sense we could probably do more to learn about our audience.

Christina echoes Stephen's comments but goes on to explain that at the Adam, they look more towards the quality of writing as a way of serving audiences.

We honestly don't anatomise our audience $[\ldots]$ in the way that say a big museum like Te Papa would do where they really do a lot of analysis of who's going to come to this show and then they try to speak to those people. We don't have the resources to do that, we don't have the audience to do that. [...] So, there will be a standard that I will set that is more to do with the quality and clarity of the writing, with a sense that we are speaking to an informed, literate audience. So, there's an assumption there that that is our audience.

At the Dowse, Courtney explains the visitor research carried out and their audience make-up.

We do a face-to-face survey that is done by our front of house staff. With that survey we are looking at where people came from, where they live, have they visited before, how frequently 
do they visit, were they here with family, have they come with children or have they not come with children and it separates out at that point - the children one, you have a few more questions about things like using the family lounge and non-children one doesn't. We ask them if they've ever visited our other museum which is Petone Settlers Museum. We ask how long their visit was, what was the duration of your visit today, we ask if they came to see a specific exhibition or for a general visit or a bunch of other things. So, one of the things that we know is that most of our visitors are coming from the Wellington region, but not necessarily from Lower Hutt, that they're regular visitors, they come several times a year and that they usually identify as coming for a general visit.

Courtney is also particularly interested in visitor motivations and meeting their needs. She explains a recently added question to their survey.

We've just started asking people in the last couple of months what benefits they felt they got out of their visit. [...] I'm interested in that - what was your motivation and was it matched by your experience? Did you come because you wanted to learn, did you come because you wanted to relax, did you come because art is a place you go for restoration or to learn things or did you come because you had to amuse your kids? Did your experience work? Which is something we'll bind in a bit to interpretation but also bind into marketing quite a lot and I do think marketing is a form of interpretation.

Melanie reinforced much of what Courtney describes, but adds detail about education audiences and the art ecosystem of the Wellington region.

...because we have strong education numbers we do seem to get a lot of young people coming in and our audience numbers suggest that the majority of people come from outside Lower Hutt, so from Wellington say, which is understandable because we are part of a network of five public art galleries within the near vicinity and people tend to go to all of them because Wellingtonians are big on their arts.

She also talked about the dual role of catering to the general public as well as members of the art community.

I think we have several roles, one is to meet the needs of people who just wander in and who don't know much about arts and would just like to see some art, that's great. Another is a really strong arts community and also our role in art history - we are a collecting institution and I think it's important we care for that as much as making contemporary projects.

At Pātaka, Mark describes that they have an anecdotal understanding of audiences and participate in the yearly Museums Aotearoa visitor survey. However, they take most of their audience information from the makeup of the local communities they are trying to serve. 
The surveys are initiated by Museums Aotearoa, so they're part of a sector wide survey. So, our interest is really more to gauge our level of visitation and engagement that we have in relation to other institutions. Usually we do pretty well, so they seem to affirm our programming rather than anything else. [...] there's more people in the galleries than you usually see at our regional institutions. That's something we feel very proud of and that's because we work hard to directly engage the local communities and we're seen as a community arts hub.

Reuben talks about carrying out consultation with stakeholder groups.

... we've held a few different kinds of workshops, because you have different audiences as well. So, for us we always do everything in Māori and English, so we've had to have different people in to talk about how we do a Māori text, why we do it that way. So, we've got to a point now where we're reflecting on that again, so we will be bringing in some Māori language speakers and readers - people who are comfortable enough to read that text and get it to see how they respond to that.

\section{Development of interpretation}

In understanding current curatorial and interpretation practice, it is important to understand the training and background of those working in these areas. The majority of participants have a background in art history and developed their interpretation skills through on-the-job experience, honing their skills over years of curatorial work. I asked participants about their career progression, how they learnt to do interpretation and if they referred to any resources when creating interpretation.

Stephen talked of getting his first job at Te Tuhi Centre for the Arts in Pakuranga, Auckland as a part time research assistant writing biographies for a group exhibition.

...you start to learn very quickly about how you summarise an artist's extensive exhibition CV into a really short word count. Then I got a full-time role at that gallery and I had an opportunity to create small texts for exhibitions under the guidance and mentorship of the senior curator there and so I've really learnt interpretation on the job. But it comes from a background of studying art history, of studying in fine arts and so you've already learnt a lot of skills of critical writing and writing about art.

Melanie had a similar experience and is currently studying towards her $\mathrm{PhD}$ in Curatorial Practice by distance learning from Monash University in Melbourne, Australia.

I came from art history where when you are doing your study you're pretty much writing little wall labels when you're writing your essays - you're writing an essay about Jacqueline Fahey and why is she important and what is this work about? It's essentially the grounding of a wall label 
text. It would be good to be more adventurous in the way that we write wall labels and things like that, make them more emotive or more open. Maybe sometimes we don't think about it too much.

Mark described his experience of informal mentoring support and networking.

I'm Pātaka's representative on TENNZ - touring exhibitions. It's a body that's a collaborative body for professionals who are curators and that's organised through Museums Aotearoa. Every 6 months we meet as a group, curators from all over the country and we share ideas about our exhibitions and this is primarily to organise opportunities for touring shows. But it's also a great opportunity to talk to other people about what they're doing and how it's been responded, sort of like a peer review in a casual sort of way and that's really good. When I first got a job here I was given a lot of mentoring support by the then senior curator. I regularly receive feedback but then that's through my colleagues in the touring exhibitions network.

I also asked the directors about whether any professional development opportunities were made available to staff. I hoped the answers to these might indicate space for improving support for innovative and reflexive interpretation strategies.

At Pātaka, Reuben talked of the professional development budget he has from the Porirua City Council to support his staff.

...we have $\$ 9000$ a year in training budget and I ask the teams during their performance reviews what training they want to do. So, Stew is doing his Masters at the moment, he's our graphic designer, so we gave a significant contribution towards that. Loreen is doing her postgrad in museum studies, our registrar $[\ldots]$ Bridget is our exhibitions officer, $[\ldots]$ she wants to go to the Kahui Kaitiaki which is the Māori museum and art gallery workers conference which tends to usually happen during the Museums Aotearoa conferences, so we'll send her to that, with flights, pay her registration and stuff like that.

Reuben also talked about doing workshops with National Services Te Pairangi and how he wants to help develop those.

I've been wanting to do a workshop, to work on developing a workshop with National Services that looks at bringing in Māori artists and museum workers from around the country and letting everybody know what the new words are for abstraction, post-modernism, all those kinds of things.

At the Dowse, Courtney explained the development opportunities.

The curatorial team tends to go to the various curatorial symposia and hui that are run. We've sent newer staff members on the National Services course - the one-day interpretation course 
that they run but that's quite a lot more museum focused than contemporary art focused. [...] So, the curators probably get most of their professional development by hanging out with other curators and doing a lot of reading themselves.

Courtney also wondered if lessons could be learnt from looking to overseas interpretation practice.

I'd say that pretty much every art museum has put out its own guidelines on how to develop interpretation which would be, I would say, 85\% overlapping and 15\% specific to the goals of that institution. It would probably be a little bit of an eye opener because most NZ contemporary art galleries are running at the level where the curators are writing the interpretation, it might get work-shopped but we're not like a Te Papa where the curators pull the ideas together and then a writing team develops them into the interpretation. So, there's probably some skills that would help curators, even if it just helps curators be more productive [...] I bet you there are a few frameworks out there that if you gave them to people they could go, 'oh shit, this is $95 \%$ what I've been doing intuitively and here's $5 \%$ of structure that I can add to it that will make me more efficient'. [...] Or 'oh that's an insight about audiences that I hadn't thought about.'

When I asked Christina if she knew of any professional development opportunities that dealt specifically with art interpretation, she answered "no" and went on to acknowledge that there is work to be done in broadening audiences through interpretation.

I think we should probably take more notice of it [changing interpretation practice] because in truth people like us, the pointy headed curators and art historians, in truth if you really dig down, we're probably only speaking to only 400 people who are like us, or 600 people or our community or our peers, those people who we're seeking, who's opinions we respect. In a sense we are speaking amongst ourselves and I think we have to be very cognisant that this can become too rarefied. We do have to also convey our enthusiasms to a broader audience to convince other people that what we're doing has value.

In whatever form, Christina believes art interpretation is about good communication.

...clear communication with an emphasis on quality and clarity and you have to believe that the art is able to do the job of capturing people in one way or another. I think it's about building trust with people who don't understand art, so many people come and apologise to me 'oh, I'm not an art specialist, I don't understand it, my opinion's not worth anything, etc. etc. I think we've got to dispel that fear, we have to say, 'whatever you make of something, that's valid.'

Providing context for a work is a delicate balancing act, requiring practitioners to weigh up artists' intentions and desires, the context of the exhibition, time and place, and the audiences' 
needs. Especially when working with living contemporary artists, galleries tend to often prioritise the artist's needs over those of the public. This is a complicated matter with competing viewpoints, requiring each exhibition to be tried on a case-by-case basis. Christina explained about her interpretation of a Colin McCahon work in a group exhibition.

My angle on that painting for that occasion was completely conditioned by the exhibition that I had to put together and therefore the wording was pitched to explain why that work was in our space for this occasion.

Christina also explains there is an educational element to providing context.

[There is] an informational level - who is this by, when was it made, what's it made out of? What are the circumstances of its making? I think that level of information is often very helpful. I also think that by placing it within a wider social or political or art historical framework, that's helping people understand why it looks the way it does.

Christina warns that it is still necessary for art to retain a freedom "to be contrary, to be confrontational, to be difficult, to be all sorts of things because that's what we expect of art." A challenge she identifies is "how would you address the potential, inherent arguments that might arise around a particular artist's practice and how do you actually allow your audience to differ from your own viewpoint on your estimation of the work."

By giving context to why the artwork was made and what the artist is trying to do, it is possible for audiences to make up their own minds about whether the artwork is successful. Stephen gives an example:

I think that there's certain artworks, like a conceptual piece by Joseph Kosuth in the '60's - we all know the three chairs artwork, who have studied art history. The picture of the chair, the dictionary description of the chair and the actual chair. I think that kind of artwork benefits from having interpretation, because if you have the context of what he's doing and if you have a sense of what he's reacting to historically, if you have a sense of what it means in the 20th century at that moment for an artist to engage in language as opposed to purely visual sensations, I think that artwork will mean a lot more.

This also requires practitioners to have a huge amount of knowledge and awareness of each artist and artwork's context as Stephen explains.

When you're operating in an art field at a certain level of seriousness, you inherit an intellectual history and art history and then you're also working in your own complex moment of time with all the specificities of the political situation, [...] You're operating in the specificities of theoretical movements and movements in philosophy and changes in world views. 
The context of the gallery these practitioners are working in also influences the interpretation. For both Christina and Stephen, the university context means that they feel a sense of responsibility to produce academic writing. They have "a particular mandate to think outside the box", according to Christina, and produce new knowledge within a teaching environment.

\section{Interpretive planning and strategic documents}

Taking a step back to look more at the workings of the galleries, I asked the gallery directors about interpretive planning and any strategic documents that their curators might look to in their interpretation work. I was surprised to find that interpretation was largely ungoverned, with only loose frameworks or a nod to a gallery's mission statement.

Christina comments about the Adam:

We have a mission and a vision and a set of values that we work to. We have also just established some exhibition principles and short-term priorities. So, there are founding documents that we have in the back of our mind. In terms of interpretation, I would say that we're more interested in producing new knowledge and communicating to, within the context of a teaching environment. We are trying to help the learning process and come up with things that haven't been said before. [...] I don't think we strategise at that interpretive level, I think where the thinking comes in is before that in terms of the exhibition and its contents and what that's about.

When I asked Courtney if interpretive planning was included in the strategic documents for the Dowse, she answered "no". She qualified this by saying:

I don't think with a team our size, so you've got two people who are writing interpretation regularly, we don't have an interpretation policy. We don't really have any documentation around what our voice is or anything like that. Curators need the freedom to speak in their own way. [...] I think it's a personal thing for curators, how much they want to forefront their own voice. [...] it's an interesting quirk of our industry in that curating is such a personal business and then when it comes to that very last step, we remove the character of the person who put all the stuff together. Because I guess they're in service of the art, so they render themselves invisible. We don't really have a tradition of star curators here. But no, we don't even really have strategic documents to that extent that an interpretation policy would fit into.

Pātaka had the most governance around interpretation. Reuben explains the gallery's strategic direction.

We've recently produced our ten-year plan which has a vision statement on there and there's about three statements on there and four strategic outcomes that we want. If I was going to 
sum it up in a single line, the goal of Pātaka is to provide our local community with a national and international level of art and cultural heritage displays which not only enrich our community but help to promote Porirua and the profile of Porirua nationally and internationally. Our key outcomes are quite explicit around the promotion of Māori and Pacific art and culture here because that has historically been a strength of this community and we are retaining that into the future, but we are expanding that also to reflect the changing demographics of the community where we have a lot of migrants coming in from Asia and other parts of the world as well.

He also explained that the gallery's strategic goals needed to be reflected in the positioning of the curatorial staff and that the gallery was looking at realigning the roles to better serve the gallery and the community.

...we're looking at strategies around how we position our curatorial teams, whether we have curators who are specifically looking at certain demographics. At the moment we currently just have an art curator that's very simple art, and the other one is social history but maybe those two could shift in terms of if we had somebody looking at maybe Maori Pacific and another looking at Asia Pacific or a community curator perhaps and then those people could shift between social history and art or they could do both at the same time.

Pātaka was the only gallery explicit about the format of wall labels which they have recently standardised. Reuben explains:

So, we have a set format now, there's an opening paragraph that introduces their idea, the main idea that the artist wants to get across and within that we try to make it general enough that general audiences could potentially read those three or four sentences and carry on without having to go into layers and layers and layers of more explaining. But then we do have one or two other paragraphs to give a bit of contextual detail for people who do want that detail and then a bio. We always do that in English and in Māori and they're always quite big, mostly for accessibility reasons for people who have seeing impairments but it's quite short, it's not a huge amount of text.

\section{Pressures and limitations}

It is all very well in an academic and theoretical context to sit in judgement of any shortcomings of interpretation practice. However, the real world is messy, with constant pressures and compromises that restrict practitioners' ability to perform best practice. I am interested in these limitations in order to better understand current practice, why things may be the way they are and to help inform any suggestions for the future. 
For Courtney, the practicalities of writing wall texts hold a number of difficulties, from picking a point of view, to keeping the word count short and dealing with the complexity of contemporary art.

...it's very hard to deal productively with ambiguity and contradiction in 250 words in a way that doesn't just sound like you're completely saying one thing and then completely saying another. So, it does tend to be simplified, which doesn't mean it has to be dumbed down, but sometimes you just have to pick one to three points and put them across. [...] So, you've hopefully shaved things down to their most efficient and effective form without losing a little bit of that fat that makes things kind of juicy. [...] I think the fat is sometimes the victim of the process of interpretation because the more plain spoken you get, sometimes that removes a bit of the flair and the joy. I think that would be the danger - everything becomes just becomes a bit flat.

Mark identified several limitations briefly before expanding on some of the problems he sees in the approaches of other galleries and their staff.

Time, money and knowledge. But I think most of all it's being outward looking, look at where you are, look at the people that surround your institution, many of whom won't cross the threshold, then ask yourself why? Why are you not relevant to them? [... Curators can] become very interested in quite high level, esoteric, deep conceptual concerns which don't necessarily engage the wider community and it can actually be quite isolating.

He also identified that matching the intentions or expectations of artists with audience needs can be difficult.

It's a matter of the artist intent and then the receptibility of your audience and trying to match them up, because often artists come from an academic background and they're used to writing quite academic texts about their works which are totally unsuitable They're fine in publications but they're totally unsuitable in the gallery context because people just won't understand what they're about. Trying to pitch them down a bit so they're more accessible is often quite a tricky process and there's a lot of negotiation that has to go on.

Reuben also echoed this point about working with living artists and being careful about framing the work in a way that an artist is happy with.

With living artists, I think you need to be really working with them, even if you are re-visioning their practice to make sure that they are, or at least what you are proposing is actually interrogating something that they were interested in or perhaps was affecting their practice, but they hadn't thought about it because I think there is a danger of creating links sometimes when there aren't links there. Because we can frame stuff out of, you can spin doctor things [...], I 
think you do have to be careful because you can get pulled up if the artist is like, no actually I don't like you framing my work in a particular way.

Stephen describes the limitations he has encountered as a curator.

The limitations are always around staffing really. So, I think that's the main challenge, there's never enough hours in the day. But I think what that limits is, from my perspective at least, from my personal challenges, what that limits is your long form research where you don't have time to get to that more significant essay for an exhibition. [...] I think what does suffer sometimes is the long form research, because there's only so much time in a day, so ideally, I'd like to have more time for that.

At the Dowse, Courtney also identified this problem around critical responses to exhibitions and the longer texts that contribute to our art history.

Now that we don't have art reviewing in Wellington newspapers, that is what's so lacking and that is what turns into art history in the future but if a critic never writes up an exhibition, it's sort of some installation photos and a bit of documentation in a folder somewhere. It never, it kind of never reaches its full potential.

Christina identified staffing and time as factors that limit the Adam's ability to connect more with teaching on campus and get more buy- in from other university departments.

... we have to do a job to explain the value of visual literacy, of what an art gallery experience can do not just for art history students or museum and heritage studies students but for a range of different disciplines. [...] I think we could get a lot more buy- in if we could somehow connect with academic staff in the right moment of their course development and that's a resourcing issue. I don't think we have enough time to do that...

Melanie identified a more psychological reason for interpretation remaining largely unchanged.

I think we easily get stuck in our ways and I think there is a sense of a standard at the Dowse that's quite hard to break. People are change averse and they don't like doing things differently. I think it just takes the energy and the passion to do it. [...] People are very territorial in these kinds of institutions because it's a competitive world, it's quite territorial and I think to get people to break out of the mould you have to actually get the whole rest of the team on board and that's not necessarily an easy job. But it's not impossible I don't think. Actually, I think people are kind of open to it. I think if there was seen a need to do it then it would happen.

If I am to pursue change in art interpretation and ask practitioners to experiment with their practices, then I will have to address and make suggestions to deal with these factors. Change can 
be daunting but it can also be exciting and liberating and if done with structure and consultation, I hope that it would lead to some very exciting results.

\section{Why interpret?}

Beyond merely what interpretation can include and how it is done, I asked practitioners why they thought art interpretation was necessary. Their answers gave insights into the moral and philosophical underpinnings of their interpretation practices and justifications for why interpretation is an essential part of their work. It is useful to understand, at an ideological level, why practitioners choose to communicate and explain information in certain ways and what they aim to offer audiences. Understanding the current position of practitioners can help inform how to shift or align thinking, give clear direction for interpretation strategies and move the practice forward.

For Reuben at Pātaka, he sees interpretation as being part of the tikanga or protocol of the art gallery and that there is an expectation from audiences that they have written information about the artworks or exhibition at the start of a space to tell them how to read the work. Reuben seemed a little exasperated with this very dogmatic approach but saw it as something demanded by the gallery as a Western paradigm.

I think of an art gallery as kind of like the western marae and there's tikanga and protocol in here and so when I come in here I'm like this is how pakeha do it, this is their place, they like it this way and if you deviate from that, they complain. Artists will always try to challenge that and academics but the people who come in, the large majority of them have been trained on how they go and view culture and that requires them to go and read a thing and to look at the stuff.

However, he goes on to explain that interpretation is also about engagement and advocacy for the arts and that interpretation is necessary in getting people to care.

But when we're trying to encourage them to engage with more difficult art, which is a hard proposition, you have to help lead them into it, give them something that, give them a reason to give a shit. Otherwise why would they? Why would they care?

The danger that Reuben identifies is that if you do not give non-art-specialists a way in to engaging with contemporary art, you just end up putting on exhibitions for an exclusive academic audience. The information provided in gallery spaces is for a broad audience, so people have a starting point. Reuben's colleague, Mark, describes interpretation as necessary "to enable and 
empower the audience to appreciate the work in as many ways and on as many levels as possible." This sums up the ethos of accessibility promoted through interpretation.

Melanie Oliver mixes the practical with the philosophical in her argument for why interpretation is necessary.

Well, I guess if you're going to bother making the work and then putting it in a gallery and all of the commitment and the money and the energy that goes towards all of those steps that get something on the wall, why would you stop there? And just leave it to the viewer to say good luck, you know? I think especially in an institution like the Dowse which is a public art institution in Lower Hutt... [We serve a] really broad range of audiences so it feels important to be able to support all those different types of engagement.

For Courtney, interpretation is all about "connecting art with people" and helping people create meaningful experiences. She talks about how their interpretation helped a visiting curator "find a pathway into what he was looking at, that was in some way helpful to him." She goes on to say:

I see the role of interpretation as being to help centre someone into, kind of conduct them into what we've created and then create something that they can sort of metaphorically walk over that strengthens their pathway [... Creating] that sense that you get inside yourself when something gets unlocked [ $\ldots$ and] a little window in your mind gets opened up and something new comes in. I think that's what I'd like people to get out of the interpretation, or at least the very basics of why have you decided to make me look at this thing.

Similarly, Christina talks about interpretation as a "layer of guidance" but that "each person that comes in [to an exhibition] can approach the show with their own processes of interpretation" and that "the very best internal text in an exhibition is that which may point at something but will not weigh down the viewer with a single interpretation." Interpretation as entry point was something that came through all the interviews in one way or another. Stephen sums up this common theme in relation to the public art gallery context:

Within public institutions, there seems to be a greater onus towards supporting a reading of the work. Providing enough information so that people don't feel as though the artwork is pretentious or patronising in its form or lofty in its thinking but to try to provide some channels into a work so that people have a way in if art isn't the thing they look at all the time. I think that's what we try to do at the Adam. We're in a university context so I think we can embrace a reasonably sophisticated kind of level of writing but at the same time we are typically trying to provide context and hopefully provide some ways into a work. 
Communicating the context of the art and the exhibition as well as providing a level of guidance around how to approach the work are common understandings of what interpretation does. This is inherently linked to the democratic and public service mission of galleries as places for everyone. The practitioners also go beyond simply relaying information in an accessible way, they aim to provide a bridge between the work and their audiences' own personal meaning-making, to unlock and inspire new ways of relating to the world. These are high ambitions but when they work, audiences are supported in creating meaningful connections between art and life.

\section{Conclusion}

I have found that interpretation in the smaller Wellington regional galleries is a largely informal and personal practice. While practitioners have similar understandings of what interpretation encompasses and why it is an essential part of exhibition making, there is little formal documentation and structure. Interpretive planning is not common, with only Pātaka having a set format for wall labels. Practitioners' understanding of audiences is largely anecdotal and, when creating interpretation, the focus is often on doing justice to the artist rather than considering how best to serve and communicate with audiences. Having developed their interpretation practice from a background in art history, it is understandable that the interviewees are aligned with artists and art historical scholarship. While this training is important as practitioners are required to be subject experts, more training to advance audience-centric interpretation practice needs to be developed in order to support meaningful engagement. This is a young field where the lack of professional development opportunities is one of the most worrying limitations identified in the interviews. Along with time and resources to adequately plan and strategise interpretation, developing a framework for institutional critique and evaluation is essential in the quest to move interpretation practice forward in our local context. In the next chapter, I discuss these limitations further and offer suggestions for how they may be overcome. 




\section{Chapter Three}

Towards Audience-centric Art

Interpretation 
Art interpretation is a subjective and often difficult pursuit, with practitioners having to balance information against storytelling, specialist language against word limits and personal flavour against institutional voice. As the previous chapter shows, currently this is an informal process of give and take, workshopping with colleagues and working within limited time and budgets to get exhibitions up on the walls. In this chapter, I argue that working on a case-by-case basis developing interpretation is inefficient and does not encourage ongoing evaluation and improvement of practices for the public. Interpretation is a relatively underdeveloped area of museum practice and a formalised interpretation framework is especially lacking in gallery practice. My research aims to address this gap by providing an overview of current understandings of interpretation, how practitioners and galleries carry out their work and an exploration of key philosophies that underpin audience-centric interpretation practice. Gallery visitors are the primary consumers of exhibition making and interpretation, therefore practitioners need to put audiences at the heart of what they do. In this chapter, I provide analysis of the case study galleries' interpretation practices, discuss the relationship between the new museology and local philosophies of interpretation and reflect on how audience-centric art interpretation might be embedded in local galleries.

\section{Continuums of interpretation practice}

The interviews illuminated not only the common understandings and trends in interpretive practice, they have also allowed me to identify issues and inconsistencies in the field. Practitioners' ways of working are influenced by the expectations and structures of the institutions they are working in. Therefore, I was interested to understand each gallery's style of interpretation, planning, structural models and to what extent they included visitor research in their practice. The following diagrams illustrate where each of my case study galleries fall on these continuums.

\section{Gallery alignment}

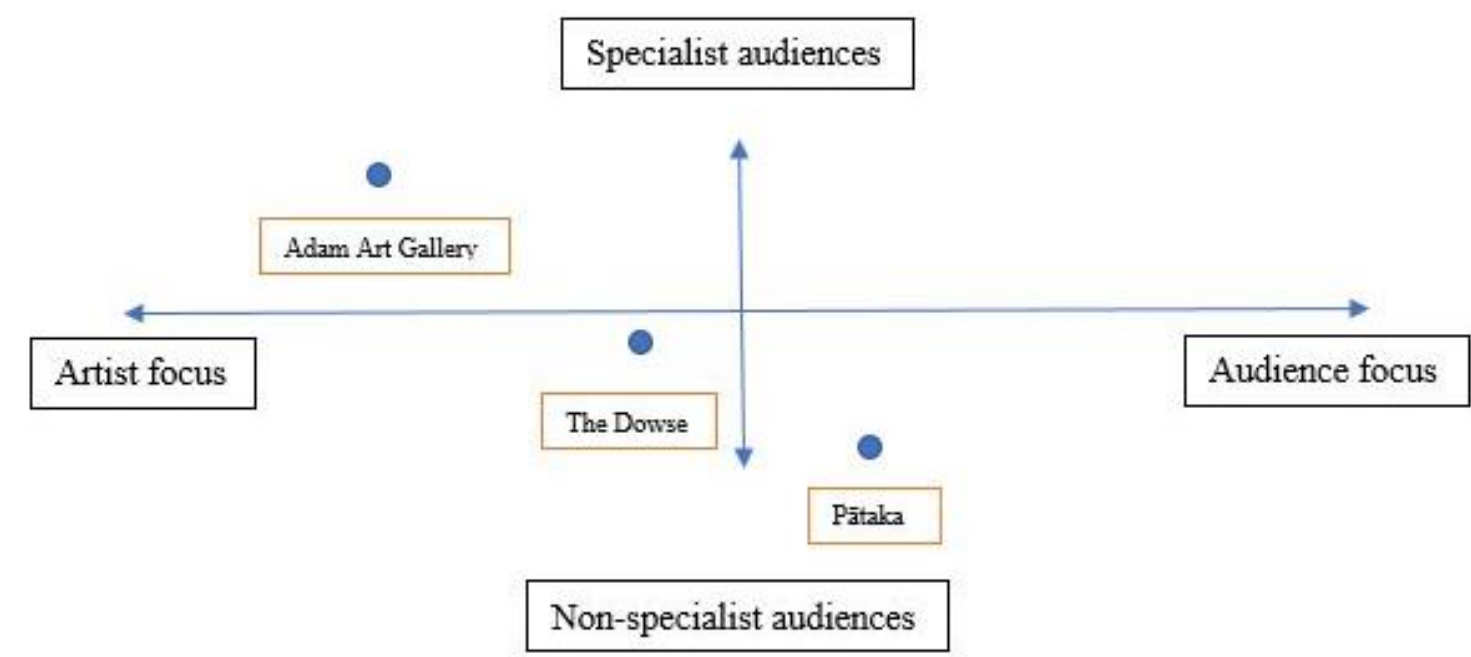


Who galleries align themselves with in terms of service and purpose has an effect on the style of interpretation they adopt. In the above continuum, I have plotted the alignment of the case study galleries against two axes - specialist to non-specialist and artist to audience alignment. Specialist to non-specialist reflects the type of language used and level of prior knowledge expected from audiences. At the Adam Art Gallery, there is a higher expectation of prior knowledge and academic level engagement as the gallery is situated on the Victoria University campus and operates within that academic setting. Stephen commented that the staff at the Adam embrace specialist language and place importance on framing their exhibitions in academic long and short form writing. The two council-funded public art galleries, the Dowse and Pātaka, use language that is more accessible to a wider cross-section of the public and artistic concepts and terms are explained rather than considered assumed knowledge. The alignment of the gallery staff is evident from their choice of language and interpretation styles and the types of audiences they see themselves as serving.

The spectrum from artist to audience alignment is a little more arbitrary as the two do not necessarily sit in opposition. All gallery practitioners must balance the needs and requirements of the artists they work alongside with those of their audiences and this inevitably involves compromise. However, the inherent or even subconscious alignment of practitioners towards these two competing stakeholders results in different styles of interpretation. I found that those aligned with artists tended to focus on the importance of contributing to art history, creating new knowledge and doing justice to the artwork with interpretation. These comments came from across all three institutions, from Christina, Stephen, Melanie and Reuben. However, due to the context of the Adam Art Gallery, this attitude was more deeply seated for Christina and Stephen. The others were tempered by the public mission of their galleries as council funded organisations. Pātaka was the gallery most aligned with audiences, with Mark commenting about the importance of being relevant to the surrounding community rather than focusing inwards on high level, esoteric, deep conceptual concerns.' Pātaka is self-consciously working to become a more inclusive gallery by creating bilingual interpretation, accessible way-finding and disability awareness. Their balance between the needs of artists and audiences is tipped towards audiences taking priority. Mark talks of working collaboratively with artists to bring their interpretation to a level where audiences will get most out of the work, bringing artists on the journey towards engaging productively with the public. 


\section{Visitor research}

\section{Consistent data gathering}

Infrequent/anecdotal

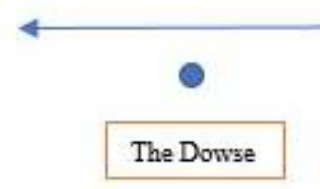

Pätaka

Adam Art Gallery

Understanding audiences through systematic and consistent data gathering can allow galleries to better cater to their audiences and create benchmarks against which to assess their successes and weaknesses. I found that, while all the galleries carry out the yearly Museums Aotearoa survey, only the Dowse gathers data throughout the year and asks visitors about their motivations and experience satisfaction. Courtney talks about the importance of asking audiences whether their expectations are matched by their experiences and how that information is used to improve interpretation as well as marketing. Pātaka uses data from the Porirua City Council about the makeup of surrounding communities to understand and cater to audiences. They also occasionally convene focus groups around particular aspects of interpretation, namely bilingual wall labels. The Adam Art Gallery has an anecdotal understanding of its audiences, especially those coming to events and public programmes which the gallery staff are present at. There is an assumption that they are writing for an 'informed, literate audience' and Christina comments that she is more concerned with the elegance and quality of their writing rather than anatomising audiences. She seems to have a distrust of using visitor research to influence interpretation. This is a common feeling I have encountered in the industry and is based largely on the understanding that visitor research simply records demographic information. Demographic information has been shown, according to John Falk, to be unhelpful when making decisions about interpretive strategies. Instead, gathering data about visitors' motivations for visiting and what they get out of their experiences is a much more useful line of enquiry. Greater understanding of the use of qualitative visitor research, even on a very small scale, would be valuable for gallery practitioners in creating audience-centric interpretation. 


\section{Interpretation planning}

Structure/Framework

Case-by-case

I was surprised to find how informal and unstructured interpretation practice is in the galleries I studied. Practitioners largely operate on a case-by-case basis when creating interpretation and there is not necessarily an institutional style or voice that is adhered to. Practitioners had largely learnt interpretation on the job and it was inherently linked with their training in art history. There is a consistent understanding that labels need to include the basic information about the work (artist, title, date, materials) and information to situate the work within an art historical, political, conceptual or economic context. However, why interpretation was done was not clearly articulated in the institutional documents and there were few links between the mission and vision of the galleries and how interpretation was to be carried out. Courtney describes the importance of curatorial freedom and Christina explains how exhibition principles and programming of exhibitions lead the interpretation. Both the Dowse and the Adam Art Gallery's curatorial staff create interpretation on a case-by-case basis, without strategic documents governing the content or style. At Pātaka, Reuben recently developed the gallery's 10-year strategic plan which includes key outcomes around audience engagement and the alignment of curatorial roles. They also recently standardised the format of wall labels for audience accessibility, making Pātaka the most structured of the galleries in terms of interpretive planning.

\section{From the new museology to local interpretive practice}

Much of the literature around new museology focuses on a visitor-centred approach where museums and galleries are seen as places of informal learning, social interaction and leisure activities. ${ }^{1}$ Addressing the quality of visitors' experiences in art galleries is an area of growing critical awareness for international practitioners. There is a growing body of knowledge that New Zealand gallery staff could learn from, including texts such as John Falk's Identity and the Museum Visitor Experience (2012) and Judy Rand's 'The Visitors' Bill of Rights' in Reinventing the Museum (2012) which offer models for understanding visitors' needs and motivations.

1 Foley and McPherson, 'Museums as Leisure'; Kirshenblatt-Gimblett, Destination Culture. 
From the interviews, there was a clear sense of public mission in the interpretation created at the Wellington case study galleries. As Melanie commented, 'I think especially in an institution like the Dowse which is a public art institution in Lower Hutt... [We serve a] really broad range of audiences so it feels important to be able to support all those different types of engagement.' Practitioners also talked about the informational and contextual aspects of interpretation as supporting audiences' readings of the works. Christina considered this as 'an informational level who is this by, when was it made, what's it made out of? What are the circumstances of its making? I also think that by placing it within a wider social or political or art historical framework, that's helping people understand why it looks the way it does.' The importance of giving non-artspecialist audiences a way into engaging with contemporary art through interpretation was an aspect articulated by Reuben. He commented, 'when we're trying to encourage them to engage with more difficult art, which is a hard proposition, you have to help lead them into it, give them something that, give them a reason to give a shit. Otherwise why would they? Why would they care?'

Practitioners in the Wellington case study galleries do echo and work towards the ideals of new museology to meaningfully engage wide ranging audiences. However, they also acknowledge that there are limitations in their practice and these reflect the inconsistencies I have noticed between what they say interpretation should do and whether they live out those principles in practice. These are not new issues but are deep-seated structural issues within the field. Writing in the 1980's, Philip Wright identified the difficulties in galleries of balancing priorities between serving art history and addressing audiences' understanding of art. This is a power struggle that is alive and well today, with galleries sitting on a continuum of alignment as discussed above. Wright also identified that explaining the context of an artwork is an essential element of interpretation because the social, political, economic and cultural contexts of a work are rendered invisible within a gallery space making it impossible for artworks to fully speak for themselves.

Something that came through in the international literature that was not evident in the Wellington, New Zealand context is the ethical imperative for institutions to make transparent their interpretation practices. Lisa Roberts argues that it is important to acknowledge that exhibitions are authored by individuals and institutions and that meaning has been constructed for a purpose. This construction is not necessarily nefarious in nature, but Roberts argues for empowering visitors to control their own meaning-making through giving audiences tools to critically approach what they are encountering. Roberts also suggests that galleries have an ethical responsibility to include non-specialist knowledge through taking an inclusive, multi-vocal and transparent approach. Especially in the council funded galleries, the Dowse and Pătaka, there is a 
deliberate choice against having curators named in the interpretation attached to their exhibitions. Courtney remarked on this 'quirk of our industry that curating is such a personal business and then when it comes to the last step, we remove the character of the person who put all the stuff together. Because I guess they're in service of the art, so they render themselves invisible.' However, making explicit to the audience the construction of exhibitions may be an interesting experiment for New Zealand galleries to consider. Somehow articulating the complexities and competing priorities of curators and artists would give audiences the tools to unpack and reflect on their gallery experiences and empower them to engage with open eyes.

\section{Why galleries need to put audiences at the heart of their work}

At the start of this research project, I had a strong sense that galleries needed to do more to make interpretation intellectually and emotionally accessible for audiences. I felt in some galleries that the spaces, language and concepts were intimidating. As a graduate of tertiary degrees in fine arts and art history, the feeling that those gallery spaces were not for me was troubling. If I, with my fairly high level of education in the arts, was uncomfortable entering and engaging with art in those galleries, then a great number of other people with less experience and knowledge must feel excluded. From a moral standpoint, this is reprehensible. Art should not be elitist and, especially in public art galleries, interpretation should offer welcoming and engaging information for a wide range of audiences. Throughout the course of the interviews, I heard from practitioners about their understandings of interpretation and their rationales for why interpretation is done in particular ways at their respective institutions. They were consistent in agreeing with my thoughts that interpretation should broaden access and understanding of art and that interpretation has a democratic function. I found myself agreeing with practitioners, that they were doing all they could within limited time and budget to cater to audiences. However, it struck me that practitioners were rarely aligned with audiences when they created interpretation. Instead, they were working on behalf of the artists or in service of art history. I gained a greater appreciation for the fact that galleries are balancing all of these competing needs from different stakeholders and causes. Nevertheless, this dissertation argues that strategic planning linking the public function of galleries with an interpretation strategy would make it possible for galleries to think critically about how they engage their diverse audiences.

Understanding more about audiences, especially their expectations and motivations for visiting galleries, will help practitioners empathise with their audiences and make decisions based more on audience needs. The texts by Falk and Rand offer insights into visitor types and motivations that can be applied to any institution without the need for each gallery to carry out its own extensive 
visitor research. Identifying and serving the needs of different audiences is something that comes more naturally to some practitioners and galleries than others. A distrust of anatomising and 'speaking to' particular audiences is an attitude that exists within the field and came through in the interviews, particularly with the staff of the Adam Art Gallery. For example, Stephen commented that he was not sure he could write interpretation for his grandmother and was 'suspicious of the idea of trying to write for another audience.' Often arguments against audience-centric interpretation are based on exclusionary understandings such as: that creating audience-friendly interpretation requires practitioners to 'dumb down' the concepts so that they lose all academic rigor, or that extensive interpretation will detract from the pure experience of an artwork. Graeme Farnell's edited volume, Interpreting the Art Museum (2015), aims to challenge and move past these exclusionary notions and hopes to encourage 'sensitive and effective' interpretation. Audiencecentric interpretation is about giving ways in to the art for as many people as possible. Personally, I want to share art with everyone who is interested, to see them excited about the creativity of artists, to reflect on concepts and how they relate to society, culture and different experiences. We need to find more ways to invite audiences into this world of art and ideas that are empowering, challenging and satisfying. In the words of Sam Ham, 'Interpretation is a provocation, not instruction. In other words, we're not trying to teach anything to anybody; we're simply trying to provoke them to deep thought about something., ${ }^{2}$

\section{How might audience-centric art interpretation be embedded in gallery practice?}

From the start of this research project, I wanted to understand local interpretation practices in order to advocate for an audience-centric approach to art interpretation for small galleries in New Zealand. This intention, along with what I have learnt from the subsequent research, has informed the development of my own approach to art interpretation. I have learnt from the knowledge of experienced curators and identified areas of frustration and opportunity through interviews with practitioners from three case study institutions in the Wellington region. I found that interpretation is a varied field encompassing many aspects of communicating with audiences including wall texts, marketing materials, exhibition design and public programmes. However, interpretation is currently an informal practice driven by individual curators who are often aligned with artists and the art historical cannon rather than with audiences. There is little policy governing how and why gallery staff create interpretation and this has resulted in an ad hoc field where evaluation and

2 Latimer, 'Art for Whose Sake?', 75. 
improvements are difficult to implement. Curators often come from a background in art history and have developed their curatorial and interpretation practice on the job rather than through academic study. There are no tertiary-level curatorial courses available in New Zealand so those wishing to pursue a qualification would have to go to Australia or further afield. This lack of formal training and academic development of the field alongside practice is a serious issue. In small galleries where curators control much of the interpretation, their training in art history dominates how they create interpretation and how they value the information they communicate to the public. This can reinforce structures of power based on canonicity where famous, often white, male painters are privileged over women, people of colour and artists working in 'low art' mediums. This was not necessarily the case in the institutions I studied, where practitioners were seeking to redress these historical imbalances. However, this pursuit was based on the personal interests of practitioners rather than on an institutional obligation. This brings us to the thorny issue of why interpretation practices should be formalised and what the underpinning philosophies are that will inspire practitioners to change.

\section{Social responsibility}

First and foremost, we must ask why galleries exist and who are they for? Are they institutions only for art experts, those of a certain class, background or income bracket? Most of us would answer 'no' - galleries are places for everyone. Interpretation is an essential aspect of making art available to the public. Practitioners agree that interpretation aims to give context to the art shown, to offer ways to engage with and 'read' the work and to open up meaning for a diverse range of audiences. I propose that the public service philosophies written into strategic documents, mission and vision statements need to be explicitly connected with galleries' policies and practices of interpretation. This gives clear direction across institutions and a benchmark against which to evaluate their performance. Combining the theories and practical models from the international literature with an understanding of local trends and understandings of interpretation from the Wellington case study galleries, I have identified social responsibility as a unifying philosophy essential to the development of audience-centric interpretation practice.

Culture is a powerful tool that helps shape society and public art institutions come with a responsibility to work in a socially conscious way. Galleries are political spaces that have historically been defined by elitism, aesthetic judgements, canonisation and wealth. Having now developed into spaces of education, reflection and leisure for broad audiences, galleries are breaking down their barriers to entry - but there is more work to be done. I aim to be an advocate for the cultural rights of all citizens, championing the right to access and understand art and the right of audiences 
to see themselves represented in the choice of artists, staff and stakeholders. This requires commitment across the board. From a programming perspective this includes the choice of artists and exhibitions, for written interpretation this includes the choice of language and, at a deeper level, the staffing of institutions affects whether audiences feel safe and welcome. This last point can be a challenge for small institutions with few staff. However, there are ways to overcome a lack of diversity by looking to surrounding communities for advice and guidance. Sustainable and collaborative working relationships with external groups or individuals need to be built on trust, reciprocity and generosity and require continual negotiation. Galleries can look to the literature and practice of new museum ethics to develop their sense of social responsibility. Janet Marstine, a leading scholar in new museum ethics, describes the central idea as:

Encouraging museums to look outward and engage with the wider world through the lens of ethics, it maintains that transparency and self-reflexivity toward the processes and authority which museums hold helps them to build trust with communities. The new museum ethics advocates placing social responsibility at the heart of museums so as to reinvigorate their mission and values toward contributing to the wellbeing of society. ${ }^{3}$

\section{Critical practice}

Becoming self-reflective as individual practitioners and at an institutional level is essential to starting the process of formalising interpretation practice. Especially in small galleries, staff are often stuck in a cycle of exhibition-making that does not allow them time or incentive to reflect on or evaluate how their interpretation is serving audiences. If we want to see improvement and meaningful change in our local art galleries, then opportunity and reason to reflect, research, prototype and develop interpretation practice needs to be made. Combining the terms institutional critique' and 'socially engaged artistic practice', critical practice describes an approach to thinking about your work in a more reflective way. This approach allows practitioners to think about their systems of knowledge, cultural production and power at an institutional level rather than at the level of critiquing an artist's place in the art historical cannon. Considering interpretation as a formal practice, with a history, set of common forms, ethics and philosophies, will make it possible for insiders and outsiders to evaluate gallery practices. Critical practice is based on a set of guidelines that fosters 'transparent, collaborative, distributed and process-based ways of working. ${ }^{4}$

3 Janet Marstine, Jocelyn Dodd, and Ceri Jones, 'Reconceptualizing Museum Ethics for the Twenty-First Century: A View from the Field', in The International Handbooks of Museum Studies: Museum Practice, ed. Conal McCarthy, First edition. (Boston, Massachusetts: Credo Reference, 2017), 69.

4 Janet Marstine, Critical Practice: Artists, Museums, Ethics (London: Taylor and Francis, 2017), 18. 
New Zealand galleries need to develop a set of processes that promote reflection and critical practice. There is an ethical and academic imperative to examine interpretation practice as an emerging field essential to the understanding of art exhibition, cultural production and community engagement. How well are we performing compared with our overseas counterparts? Are we truly advocating for and fulfilling the cultural rights of a diverse population? Are audiences satisfied by their experiences in galleries? These may be difficult questions but they need to be asked and the industry needs to adequately fund, or create policy to implement, this kind of research and reflection.

\section{Collaboration}

Interpretation is a function of many roles within a gallery and is not solely the domain of curators. Creating a collaborative working environment where all staff have input and access to interpretation practice will allow galleries to create cohesive interpretive strategies across all interpretation channels. This will not only encourage internal dialogue and feedback but will diversify the voices included in interpretation. Bringing together knowledge from many backgrounds and disciplines, not solely art history, will strengthen cross-disciplinary understandings of art and communicate those to audiences. Front of house staff are an underutilised group who can offer valuable insights into visitor needs, frustrations and typical behaviour. They are likely to come from more diverse backgrounds than curatorial staff and, if asked, can offer different and practical expertise. Involving front of house staff in the creation of interpretation also encourages passion and buy-in from those staff who have most direct contact with visitors. They can help tell the stories that maybe cannot quite fit into the word limits of wall labels and offer anecdotes tailored to the visitors they encounter - creating unforgettable experiences for audiences. Face to face encounters are often the most rewarding for both staff and visitors and they help create meaningful dialogue between the institution and the public. Education and public programmes are great opportunities for collaboration and cross disciplinary discussions, especially when galleries partner with communities or external experts. Generously hosting differing views and competing ideas builds trust in the gallery as a space for open debate and works towards making galleries essential to community life.

Working collaboratively with artists, audiences, communities, councils, funders and stakeholders can offer opportunities for personal and institutional growth. Galleries do not work in isolation but are influenced by and are influencers of their local social, economic and political landscape. The social participation of staff in the world beyond the gallery walls helps keep the exhibitions relevant and connected to the issues of their constituency. As Nina Simon encourages, 
breaking down barriers to entry requires building new doors into the content for new audiences. To do this in a meaningful and sustainable way requires genuinely listening to those groups who you would like to invite in. Getting outside your comfort zone and entering unfamiliar places will help you empathize with those people who may be too afraid to cross your threshold. Look out for things that make you feel wary or welcome and seek to address those within your own institution. Looking for partners outside your institution can help address gaps in knowledge or resource and inspire new directions for interpretation. Cooperation with generosity and empathy, where both parties are enriched by their experiences, is a sustainable model for audience development, increasing diversity and developing a multi-vocal approach. Collaboration is a chance for everyone to learn, to increase mutual understanding and to enhance meaningful career and personal development.

\section{Conclusion}

Interpretive planning, especially for art interpretation, is a young field that is only just beginning to build a shared body of knowledge, language and practice. According to Judith Koke, in her foreword to Interpreting the Art Museum, it is through building shared experience, research and vocabulary that the profession will be able to develop the strong evidence necessary to supporting true institutional change. ${ }^{5}$ Critical reflection on interpretation is sorely lacking in the Wellington region and within the larger New Zealand context. Some of the limitations identified in my research were the lack of critical responses to exhibitions, competitive and territorial atmosphere among peers and lack of time and mechanisms to evaluate exhibitions as part of the gallery's cycle of programming. These are serious short-falls that need to be addressed if the field is to evolve and thrive. At an industry level, there needs to be support, networking and training opportunities for practitioners to develop their interpretive practice coupled with evaluation and critical discussion. Practitioners can look to overseas examples of innovative interpretation practice for inspiration but there also needs to be an institutional desire to make change happen. Galleries need to develop their strategic planning, policies and evaluation methods to support development of art interpretation as a professional practice.

5 Koke, 'Foreword', 11. 


Conclusion 
Art interpretation is a complex area of curatorial and exhibition-making practice and an undertheorized topic within museum and gallery studies. My research aims to address this gap in critical discussion and understanding of art interpretation practice in a local context. Having gained an appreciation for the ideas, concepts and philosophies of audience-centric interpretation present in the international literature, I had a strong foundation from which to tackle my overarching research question:

\section{How might small-medium New Zealand public art galleries enhance the diversity and accessibility of visitor experiences through taking a more audience-centric approach to art interpretation?}

Taking a qualitative case study approach, I interviewed directors and senior curatorial staff at three public art galleries in the Wellington region: Pātaka Art + Museum, The Dowse Art Museum and the Adam Art Gallery. Using semi-structured interviews as my primary data collection method, I took an iterative, grounded-theory approach which allowed me the flexibility to learn and adapt questions throughout the process. Secondary research questions focused the interviews on finding out the current state of interpretation practice and understanding whether audiences' needs and motivations were considered and/or audience groups consulted as part of the process of developing interpretation. The limitations of my research include the small and selective sample of practitioners interviewed and a specific focus on the Wellington region rather than sampling from across the country. This means that my findings are only generalisable to a certain extent and that, by only interviewing directors and curatorial staff, I am not able to gain a full picture of interpretation practice within small-medium galleries. Further research would be useful in understanding the internal dynamics between staff creating or involved in interpretation including educators, marketing and front-of-house staff as well as curators and how those internal interactions might affect the visitor experience. Also, audience research asking gallery visitors and non-visitors what their expectations, motivations, feelings and needs are in relation to art interpretation would be complementary to my study and valuable in furthering our understanding of the effect of different styles and forms of interpretation.

Coming back to my research methodology and findings - having gathered the primary data through interviews, I transcribed and analysed the content for common themes, trends and patterns. I found that interpretation practice is largely informal, with little or no policy or development frameworks in place and is developed on a case-by-case basis for each exhibition. Galleries and curators tend to be aligned with artists and the art historical canon rather than with audiences. I also found that there is little visitor research carried out that aims to understand 
visitors' needs and motivations for attending galleries, let alone processes for incorporating that feedback into interpretation. Practitioners are conscious of the constraints and challenges they face including limited time, money and staffing affecting their ability to create long form critical writing, carry out consultation and gain audience feedback. An absence of specific art interpretation training and development opportunities is identified as an industry-wide issue. However, all practitioners agree that the aim of interpretation is to make art and exhibitions accessible, informative and interesting for a broad range of audiences and offer a springboard for personal meaning-making.

\section{Contribution}

There has been very little research carried out that explores interpretation practice in smallmedium New Zealand public art galleries. This was a surprise to me given that interpreting art is a primary function of all galleries. Practitioners, given their training in tertiary level art history, tend to draw on the research and writing styles of that field. When they create interpretation, they seek to understand and communicate the practices of artists, groups or movements and give context through outlining the social, cultural, political and art historical background of the work. What I propose is that practitioners and academics begin to unpack art through a form of professional interpretive practice - a practice that changes over time and under different social, cultural and political conditions. In essence, encouraging the sector - from individual practitioners through to governing bodies - to be more reflective about the work of galleries in creating and communicating knowledge about art. I hope my research is a starting point for conversations around developing, as Koke describes, shared experience, research and vocabulary for interpretation practice in New Zealand. In Chapter three I discussed current practice and offered ethical and philosophical reasons why art interpretation is necessary and how galleries might take a self-conscious, critical approach to interpretation practice. Below, I recommend a set of principles and strategies developed from examples in the international literature and from the findings of my research that will help galleries work towards a more audience-centric and reflective approach to interpretation.

Art interpretation is a particularly complex area that involves aesthetic judgements, the context and meanings of an artwork and the artist's intentions and desires, all balanced against the needs, motivations and attention span of audiences. I found that there is a lack of specific art interpretation training and development opportunities in New Zealand, especially for smaller institutions that do not have teams of interpreters or writers. Even within museum and heritage studies courses, gallery practice is on the periphery, so how can art interpretation practice in New Zealand become vital, relevant and world leading? Firstly, gallery professionals need to be 
supported with time, resources and training opportunities to develop their own practices of interpretation and become more familiar with their audiences' needs and motivations. Secondly, institutions need to develop policy, strategy and planning documents that govern why and how interpretation should be done and actively advocate for an audience-focused approach. Thirdly, industry bodies responsible for setting standards and offering training - such as National Services Te Paerangi and Museums Aotearoa - need to value and promote interpretation as essential to gallery practice and create a culture of reflection and innovation backed up by qualitative visitor research. Major industry-wide changes are necessary if art interpretation in this country is to become truly diverse and accessible. My research contributes a baseline understanding of current interpretation practice in the Wellington region that others will be able to build from or compare against. I also suggest ways in which people at all levels within the industry might move practice forward so that audiences are empowered to engage and make meaning from their experiences in our public art galleries.

\section{Recommendations}

I found that interpretation practice is often a highly subjective pursuit which aims to create personal and subjective experiences for audiences. Art is, after all, complicated, contrary and individual, making a one-size-fits all model of interpretation impractical and limiting. However, I argue that having a set of principles to guide interpretation will greatly benefit both galleries and their audiences. Bringing together what I have learnt from the literature and my own research, I have developed a set of principles which are outlined below. These are general guidelines which, when applied to the practice of art gallery professionals, aim to help develop accessible and meaningful audience-centric art interpretation.

\section{Principles}

Art is for everyone

Not in the sense that everyone has to engage with or like all art but that everyone has the capacity to resonate with art in their own way. Interpretation should not be a barrier to art appreciation but a bridge and a support for engagement with art. Art belongs to every culture, class, and background - it is not a pursuit only for the rich or the intellectual. Interpretive text needs to be clear and concise and offer a way into the artwork/ideas/concepts/narrative for a spectrum of audiences.

This principle is based on the philosophies of New Museology which champion galleries and museums as democratic spaces for informal learning, social interaction and leisure, which celebrate 
and recognise diversity and which value and encourage personal meaning-making. This also reflects the strong sense of social responsibility that practitioners displayed when talking about why art interpretation is necessary. They agreed that everyone has the capacity to appreciate and engage with art and interpretation aims to offer a way in to the art for as diverse a range of audiences as possible.

\section{Balance the needs of artists and audiences}

Galleries are a bridge between artists, their work, their practice, techniques and ideas and the public, with their own set of expectations, needs and motivations. Serving both in a meaningful and respectful way is essential to good interpretation. Swaying too much towards one over the other will do a disservice to the potential of the art to engage audiences and convey the intention of the artist.

As Melanie described, 'if you're going to bother making the work and then putting it in a gallery and all of the commitment and the money and the energy that goes towards all of those steps that get something on the wall, why would you stop there? And just leave it to the viewer to say good luck, you know?' Interpretation needs to respect both the effort and progress of an artist as well as the needs and motivations of visitors. Connecting art with audiences is the aim.

\section{Context is key}

Referring to the whole spectrum of interpretation - from the context of the gallery, the exhibition, and the space, right down to the specifics of the artwork: the artist, title, date, materials, reason behind its making, social, cultural, political, historical background - the context is an essential part of interpretation. It informs the audience's reading of the work and is interpretive in nature.

Philip Wright points out that the context of an artwork's making and the artist's intentions are rendered invisible in a gallery setting, making it essential for interpretation to fill that gap in knowledge for non-specialist audiences. Christina described how contextual information helps people understand why an artwork looks the way it does and why it has been included in an exhibition. The context of both the artwork and the exhibition are essential pieces of knowledge that need to be conveyed to audiences to make the gallery's work transparent and to assist audiences in constructing meaning.

\section{Topical, timely and relevant}

Exhibitions and interpretation need to be responsive to what is happening outside the gallery so that they become relevant to those who visit. Galleries and museums are civic spaces that act 
as forums where subjects and issues can be brought to attention. We should not be afraid of being political, of having a view or inviting critical discussion - but interpretation is essential in setting up an informed and safe space to host debate.

Christina proposed these three attributes - topical, timely and relevant, saying, 'I think people involved in putting on exhibitions and working as we do, that we have a responsibility to having knowledge and understanding and responsiveness so that we can do things that are relevant and timely.' The real strength of responsive and relevant programming is the sense of urgency and passion that practitioners can put into their work. This passion shines through the interpretation and has the ability to connect deeply with audiences.

\section{Respect and empower audiences}

Audiences bring their own experiences, knowledge, emotions and motivations to their interactions with art and art interpretation. This needs to be acknowledged when developing interpretation to allow for multiple readings of a work or exhibition and to give audiences enough information to be able to relate what they are experiencing to their own personal history. We have enormous capacity to make meaning for ourselves and draw our own conclusions - interpretation should encourage and support this.

Mark described the purpose of interpretation as 'to enable and empower audiences to appreciate the work is as many ways and on as many levels as possible.' Giving audiences the tools to engage meaningfully and critically with the art and with the gallery is essential to good interpretation practice. As Lisa Roberts asserts, 'the work of interpretation becomes an act of empowerment, because it provides visitors with both the knowledge and the consent to engage in critical dialogue about the messages museums present'.

\section{Practise empathy}

Practising empathy helps practitioners better understand and cater to where audiences are coming from, why they visit galleries and what they want out of their experiences. Whether it is to learn, grow, reflect, see beautiful things, share an experience with others or be inspired, interpretation should support audiences in making their own meanings. No-one wants to feel talked down to or made to feel out of their depth and foolish for not knowing certain information. Empathy also encourages practitioners to be sensitive to audience needs when designing

1 Roberts, 'Changing Practices of Interpretation', 158. 
exhibitions for pleasant or engaging experiences, including having adequate places to rest, appropriate lighting, signage, readable wall labels and interesting content.

I want to create interpretation that is humble, informative and generous to visitors. Listening to audience needs and gathering their thoughts will inform the decisions made at institutions to the benefit of all audiences. An added benefit of catering meaningfully to your audiences is that they will become advocates for your organisation, will trust you and be open to having new and even challenging experiences in your gallery. Practising putting yourself in the shoes of others, to see things from their perspective, is an act of reflexivity that will move interpretation practice forward and encourage more productive relationships between practitioners, institutions and audiences.

\section{Strategies}

Below, I outline a number of strategies, sourced from both the international literature and local practice, that will help practitioners put the above principles into practice. These strategies are aimed at overcoming the limitations identified by practitioners in their current working situations, including lack of time, staffing and opportunity for development. They also aim to change the alignment of practitioners from being art history focused, to becoming more audience focused. Only by placing audiences at the heart of interpretation practice will practitioners be able to genuinely connect art with the needs and personal meaning-making of gallery visitors.

Developing strategies for audience-centric interpretation and engagement can start at a personal level. However, they also need to be supported by institutional frameworks. In order to put audiences at the centre of interpretation practice, galleries may need to re-focus their processes to prioritise their public and democratic functions. There are a number of strategies that would make good starting points for individual practitioners who want to become more audience-focused in their interpretation.

\section{Practitioner-level strategies}

- Workshop interpretation with other staff, audiences or stakeholders.

- Think about user experience - from language to lighting and seating - how will audiences move through the space and relate to the material?

- Involve front of house staff in interpretation development. They know intuitively and anecdotally how audiences will react to interpretation and navigate space - they are an underutilised resource. 
- Talk to audiences and/or conduct qualitative visitor research and use this information to improve and align interpretation with audience needs and motivations.

The next set of strategies would be harder to institute as an individual practitioner because they involve change at an institutional level. These strategies are more likely to work as top-down approaches that explicitly link the public service mission of galleries in their policy and strategic documents to interpretation practice. I was surprised to find that the case study galleries had little, if any, policy around interpretation. This is something missing in the field that, if rectified, could give galleries greater opportunity for reflective practice and to evaluate how their interpretation performs against set benchmarks. I am not suggesting that interpretation practice needs to be nailed down to such an extent that there is no flexibility or space for experimentation. Quite the opposite in fact. I assert that by having a set of guiding principles and strategies that focus on the needs of audiences, there is much more incentive to be creative and really serve the public with empathy and openness.

\section{Gallery strategies}

I present the following strategies as ways for galleries to be clearer about the purpose and direction of their interpretation and to build the competencies of their staff.

- Develop an explicit framework for interpretation that aligns the mission and vision of the gallery directly with how and why interpretation is done.

- Clear road map between the two.

- Build in flexibility dependent on context (exhibition, artist, gallery, audience).

- Build in reflection and feedback into the exhibition cycle.

- Make change in a meaningful and considered way based on qualitative visitor research (surveys, interviews, focus groups).

- Iterative exhibition-making where interpretation is developed and evaluated against a set of gallery or exhibition specific criteria.

- Move practice forward - workshop ideas and take risks.

- Adequately fund professional research and development.

- Make interpretation practice an explicit area of professional development. 
- Make resources and time available for staff to pursue knowledge and training related to improving interpretation practices.

From an industry perspective, I found that there were few training opportunities that focused on art interpretation practice. While there are workshops on interpretation run by National Services Te Paerangi, they tend to focus on museum interpretation and do not cover the specificities of art interpretation. If there is a desire to move interpretation practice forward for art galleries in New Zealand, I would suggest the following strategies at a national level, led by Museums Aotearoa and National Services Te Paerangi.

\section{Industry strategies}

- Art interpretation-focused training opportunities.

- These could include workshops, seminars, guest lectures, panel discussions.

- Have a cross-disciplinary approach that includes curatorial, public programmes, exhibition design and front of house staff in order to encompass a broader understanding of interpretation, beyond wall labels.

- Include Reuben's suggestion of creating a workshop with National Services Te Paerangi that brings together Māori artists and museum workers to discuss Māori translations of art-specific words.

- Fund and make available exchange and mentoring programmes with overseas galleries, experts and practitioners.

- Sector commitment to qualitative visitor research to underpin, evaluate and inform the direction of audience-centric art interpretation.

- As well as the Museums Aotearoa survey, which collects demographic information, incorporate or run a parallel qualitative survey regarding motivations, values, expectations and satisfaction with interpretation.

- Institute a forum for reflective discussion and professional feedback.

- Create an online discussion forum where practitioners can share thoughts or resources relating to art interpretation. 
- This would be a chance for practitioners working in small institutions to be connected to a network, get feedback and have a sounding board for ideas.

- Fund and support the development of research and theory for interpretation practice.

- Formalising the field of interpretation in New Zealand will require academic research, reflection, writing and critique to mature its development.

There are many ways to approach change for the sector as I have outlined above and these changes can, and need to, be driven from all levels within the industry. Each practitioner and each gallery should consciously consider their purpose and the ideals they stand for, reflecting on how they are activating those through practice. I have outlined a number of moral and philosophical reasons for audience-centric art interpretation including social inclusion, the democracy of galleries as civic spaces for all citizens, the importance of empowering personal meaning-making and acknowledging and celebrating art as a subjective, complex form of creativity. Art appreciation is an acquired skill that galleries need to support and they are one piece in a larger puzzle of valuing culture and creativity. If galleries are to break down the barriers to entry and engagement that many people feel, their work needs to become more relevant to more people. I am inspired by Nina Simon's vision of relating to audiences through relevance. As she comments, 'something is relevant if it gives you new information, if it adds meaning to your life, if it makes a difference to you. It's not enough for something to be familiar, or connected to something you already know. Relevance leads you somewhere. It brings new value to the table'. ${ }^{2}$ I want to bring new value to both institutions and audiences. As an emerging practitioner in the world of art interpretation, I am driven by the notion that our work has the potential to connect audiences with art in meaningful ways.

2 Simon, The Art of Relevance, 29. 



\section{Appendix: Interview questions}

\section{Overarching questions (to ask all participants):}

- How do you feel about the phrase "Art should speak for itself”?

- Describe all the types of interpretation used at your institution?

- Why is art interpretation necessary?

- Who is interpretation for?

- What is the desired outcome of interpretation? How do you know if it is effective?

- What does effective or outstanding art interpretation include? Please give examples.

\section{For gallery directors:}

\section{Current practice}

- Is interpretive planning included in your organisation's strategic documents?

- Does your gallery have an interpretive plan/are interpretive plans developed for individual exhibitions?

- Who is responsible for interpretation/interpretive planning within your organisation and why?

- How do you broaden access via interpretation?

\section{Consultation}

- Does your organisation carry out any consultation (with audiences, other professionals, artists or stakeholders) about its interpretation? Who with? Why?

- What kinds of visitor research does your organisation carry out?

- Does any visitor research include information/questions to help you evaluate the effectiveness of your interpretation?

- How is any feedback/information from consultation used? What impact does it have?

\section{Evaluation and improvement}

- Are you satisfied with your gallery's art interpretation? Why?

- Does it serve your mandated audience, strategic goals and organisational vision?

- What professional development is available around interpretive practice for your staff? What support might they need? 
- I intend to create a short resource about audience-centric art interpretation, encouraging practitioners to ask and answer high level questions about who and what their interpretation is for - do you think there be interest in such a guide?

- What would you like to see included? What are some things it should consider?

- What factors need to be considered when developing interpretation?

\section{For curators:}

\section{Current practice}

- Is interpretation part of your professional role?

- Are you the staff member primarily responsible for interpretation? Do you share responsibility with anyone else in the institution?

- Who is the audience you have in mind when creating interpretation?

- How do you meet different audiences' needs through interpretation?

- Is there an overarching organisational interpretive plan/framework that guides you?

\section{Consultation}

- Who is your audience made up of? How do you know? (anecdotal, visitor research, observation, community make up from census/council information)

- What information about your various audiences' needs or motivations enables you to create appropriate interpretation?

- Do you ever work collaboratively with audiences/artists/stakeholders to create interpretation? Please give some examples.

- Who are the diverse communities that your institution seeks to serve? How might you improve diversity and accessibility?

\section{Evaluation and improvement}

- What factors would enable better interpretation to be created? (Time, money, resources/information, professional development)

- Do you refer to any reference guide, book or framework when creating interpretation? If so, what are your go to resources?

- What other information or guidance would be useful?

- What kind of support/opportunity/professional development would enable you to improve your interpretive practices?

- What factors need to be considered when developing interpretation? 


\section{Bibliography}

Adam Art Gallery. 'Vision \& Mission'. Accessed 9 March 2018. http://www.adamartgallery.org.nz/about-exhibitions/vision-and-mission-statement/.

Anderson, Gail. Reinventing the Museum: The Evolving Conversation on the Paradigm Shift. 2nd ed. Lanham, Md.: Altamira Press, 2012.

Baker, Claire Adele. 'Good Intentions: A Case Study of Social Inclusion and Its Evaluation in Local Public Art Galleries’, 2014. http://researcharchive.vuw.ac.nz/handle/10063/3728.

Barker, Emma, ed. Contemporary Cultures of Display. Art and Its Histories. New Haven \& London: Yale University Press, 1999.

Barrett, Terry. Interpreting Art: Reflecting, Wondering, and Responding. New York: McGraw-Hill, 2002.

Barthes, Roland. 'The Death of the Author'. The Book History Reader 2 (2002): 277-280.

Barton, Christina. Interview: Adam Art Gallery - Director, 26 September 2017.

Bayans, Kristin, Mike Murawski, and Phillipa Pitts. 'Building Meaningful Interpretation Around Unsettling Contemporary Art'. In Interpreting the Art Museum, 176-91. Edinburgh: Museums Etc., 2015.

Beck, Larry, and Ted T Cable. The Gifts of Interpretation: Fifteen Guiding Principles for Interpreting Nature and Culture. Urbana, IL: Sagamore Publishing, 2011.

Black, Graham. The Engaging Museum: Developing Museums for Visitor Involvement. Psychology Press, 2005.

Booth, Kate. 'The Democratization of Art: A Contextual Approach'. Visitor Studies 17, no. 2 (2014): 207-221.

Burnham, Rika, and Elliott Kai-Kee. Teaching in the Art Museum: Interpretation as Experience. Getty Publications, 2011.

Butler, Shelley Ruth, and Erica Lehrer, eds. Curatorial Dreams: Critics Imagine Exhibitions. McGillQueen's University Press, 2016.

Chamberlain, Gregory, ed. The Radical Museum: Democracy, Dialogue \& Debate. The Museum World Book Collection. Milton Keynes: Museum Identity, 2011.

Chan, Sebastian, and Aaron Cope. 'Strategies against Architecture: Interactive Media and Transformative Technology at the Cooper Hewitt, Smithsonian Design Museum'. Curator: The Museum Journal 58, no. 3 (1 July 2015): 352-68. 
Cleland, Stephen. Interview: Adam Art Gallery - Curator, 12 September 2017.

Corriveau, Bethany. 'A Spectrum of Experience: Creating Interpretive Programs for Adults'. In Interpreting the Art Museum, 320-47. Edinburgh: Museums Etc., 2015.

Costache, Irina Dana. The Art of Understanding Art. Chichester, West Sussex, UK; Malden: WileyBlackwell, 2012.

Creative New Zealand. 'About Creative NZ'. Accessed 9 March 2018. http://www.creativenz.govt.nz/about-creative-new-zealand.

- 'Research and Reports'. Accessed 9 March 2018. http://www.creativenz.govt.nz/development-and-resources/research-and-reports.

Davidson, Lee. 'Visitor Studies: Toward a Culture of Reflective Practice and Critical Museology for the Visitor-Centered Museum'. In The International Handbooks of Museum Studies. John Wiley \& Sons, Ltd, 2013.

Davidson, Lee, and Pamela Sibley. 'Audiences at the "New" Museum: Visitor Commitment, Diversity and Leisure at the Museum of New Zealand Te Papa Tongarewa'. Visitor Studies 14, no. 2 (1 July 2011): 176-94.

de Botton, Alain. Art as Therapy. London: Phaidon Press Ltd, 2013.

Denscombe, Martyn. The Good Research Guide: For Small-Scale Social Research Projects. McGraw-Hill Education (UK), 2014.

Ernst, Dorothea, Charles Esche, and Ulrike Erbslöh. 'The Art Museum as Lab to Re-Calibrate Values towards Sustainable Development'. Journal of Cleaner Production 135 (2016): 14461460 .

Falk, John H. Identity and the Museum Visitor Experience. Routledge, 2012.

Farnell, Graeme, ed. Interpreting the Art Museum. Edinburgh: Museums Etc., 2015.

Foley, Malcolm, and Gayle McPherson. 'Museums as Leisure'. International Journal of Heritage Studies 6, no. 2 (2000): 161-174.

Friend, Reuben. Interview: Pātaka Art + Museum - Director, 5 October 2017.

Fritsch, Juliette. Museum Gallery Interpretation and Material Culture. Routledge Research in Museum Studies; 2. New York: Routledge, 2011.

Grøn, Karen. 'Empower the Audience! How Art Museums Can Become Enriching Creative Spaces for a Wider Audience through Deliberate and Strategic Use of Experience and Learning Theories'. In Museum Gallery Interpretation and Material Culture, 204-20. Routledge Research in Museum Studies; 2. New York: Routledge, 2011. 
Gurian, Elaine Heumann. 'Museum as Soup Kitchen'. Curator: The Museum Journal 53, no. 1 (1 January 2010): 71-85.

Ham, Sam H. Interpretation: Making a Difference on Purpose. Golden, Colorado: Fulcrum Publishing, 2013.

Hems, Alison, and Marion R. Blockley. Heritage Interpretation. Routledge, 2006.

Hooper-Greenhill, Eilean. 'Changing Values in the Art Museum: Rethinking Communication and Learning'. International Journal of Heritage Studies 6, no. 1 (1 January 2000): 9-31.

- Museums and the Interpretation of Visual Culture. London and New York: Routledge, 2003.

'How Museums Can Help Promote Empathy'. Museum Hack, 8 March 2017. https://museumhack.com/museums-promote-empathy/.

Howard, Peter. Heritage: Management, Interpretation, Identity. A\&C Black, 2003.

Hutchins-Pond, Mark. Interview: Pātaka Art + Museum - Curator, 5 October 2017.

Jimson, Kerry. 'Translating Museum Meanings: A Case for Interpretation'. In The International Handbooks of Museum Studies, 2015.

Johnston, Courtney. Interview: Dowse Art Museum - Director, 24 October 2017.

Jung, Yuha. 'The Art Museum Ecosystem: A New Alternative Model'. Museum Management and Curatorship 26, no. 4 (2011): 321-338.

Kester, Grant H. Conversation Pieces: Community and Communication in Modern Art. Berkeley: University of California Press, 2004.

King-Wall, Riah. 'Path to Accessibility: The Current State of Disability Access in Aotearoa New Zealand Museums', 2016. http://researcharchive.vuw.ac.nz/handle/10063/5350.

Kinsley, Rose Paquet. 'Inclusion in Museums: A Matter of Social Justice'. Museum Management and Curatorship, 2016, 1-17.

Kirshenblatt-Gimblett, Barbara. Destination Culture: Tourism, Museums, and Heritage. University of California Press, 1998.

Koke, Judith. 'Foreword'. In Interpreting the Art Museum, edited by Graeme Farnell. Edinburgh: Museums Etc., 2015.

Lasser, Ethan W. 'An Unlikely Match: On the Curator's Role in the Social Work of the Museum'. Museum Management and Curatorship 27, no. 3 (2012): 205-212.

Latimer, Sue. 'Art for Whose Sake?’ In Museum Gallery Interpretation and Material Culture, 67-79. Routledge Research in Museum Studies; 2. New York: Routledge, 2011. 
Manabe, Makoto, and Lois Lydens. 'Making Connections: Using Mobile Phones as a Museum Tool'. Journal of Museum Education 32, no. 1 (2010): 27-34.

Marstine, Janet. Critical Practice: Artists, Museums, Ethics. London: Taylor and Francis, 2017.

—. 'The Contingent Nature of the New Museum Ethics'. In The Routledge Companion to Museum Ethics: Redefining Ethics for the Twenty-First Century Museum. Florence, UNITED STATES: Taylor \& Francis Group, 2011.

- What a Mess! Claiming a Space for Undergraduate Student Experimentation in the University Museum'. Museum Management and Curatorship 22, no. 3 (2007): 303-315.

Marstine, Janet, Jocelyn Dodd, and Ceri Jones. 'Reconceptualizing Museum Ethics for the TwentyFirst Century: A View from the Field'. In The International Handbooks of Museum Studies: Museum Practice, edited by Conal McCarthy, First edition., 69-96. Boston, Massachusetts: Credo Reference, 2017.

Mason, David D. M., and Conal McCarthy. “The Feeling of Exclusion”: Young Peoples' Perceptions of Art Galleries'. Museum Management and Curatorship 21, no. 1 (1 January 2006): 20-31.

Mauro, Alessandro. 'The Deviation from the Norm: Curating Photographs in the Internet Age'. In Photoshow: Landmark Exbibitions That Defined the History of Photography Alessandra MAURO | Asia Art Archive, 9-15. Rome: Contrasto, 2014.

McCarthy, Conal. 'Theorising Museum Practice through Practice Theory: Museum Studies as Intercultural Practice'. In The Routledge International Handbook of Intercultural Arts Research, by Pamela Burnard, Elizabeth Mackinlay, and Kimberly Powell, 24-30. London: Taylor \& Francis Group, 2016.

McLean, Kathleen. 'Museum Exhibitions and the Dynamics of Dialogue'. Daedalus 128, no. 3 (1999): 83-107.

Meszaros, Cheryl. 'Interpretation and the Art Museum: Between the Familiar and the Unfamiliar'. In Museum Gallery Interpretation and Material Culture. Routledge Research in Museum Studies; 2. New York: Routledge, 2011.

Morris Hargreaves McIntyre. 'Culture Segments'. Accessed 9 March 2018. https://mhminsight.com/articles/culture-segments-1179.

Museums Aotearoa. 'Museums Aotearoa'. Museums Aotearoa. Accessed 9 March 2018. http://www.museumsaotearoa.org.nz/.

'Museums Aotearoa Code of Ethics 2014'. Accessed 9 March 2018. http://www.museumsaotearoa.org.nz/sites/default/files/ma_code_of_ethics_br_2014_ v5_web_0.pdf. 
National Services Te Pairangi. 'Resources and Reports'. Museum of New Zealand Te Papa Tongarewa, Wellington, NZ, 9 February 2016. https://www.tepapa.govt.nz/learn/formuseums-and-galleries/how-guides/resources-and-reports.

Oliver, Melanie. Interview: Dowse Art Museum - Curator, 13 September 2017.

Pātaka Art + Museum. 'History'. Pātaka. Accessed 9 March 2018. https://www.pataka.org.nz/about-us/gallery-history/.

Rand, Judy. 'The Visitors' Bill of Rights'. In Reinventing the Museum: The Evolving Conversation on the Paradigm Shift, 2nd ed., 315-16. Lanham, New York, Toronto and Plymouth, UK: Altamira Press, 2012.

Roberts, Lisa C. 'Changing Practices of Interpretation'. In Reinventing the Museum: The Evolving Conversation on the Paradigm Shift, 2nd ed., 144-62. Lanham, New York, Toronto and Plymouth, UK: Altamira Press, 2012.

Sandell, Richard. 'Museums as Agents of Social Inclusion'. Museum Management and Curatorship 17, no. 4 (1998): 401-418.

Schloder, John E., Marjorie Williams, and Diane DeBevec. The Visitor's Voice: The Cleveland Museum of Art. Edited by C. Griffith Mann. Malibu, CA: Getty Center for Education in the Arts, 1993.

Sekules, Veronica, Maria Xanthoudaki, and Les Tickle. Researching Visual Arts Education in Museums and Galleries: An International Reader. Springer Science, 2003.

Silverman, Lois H. The Social Work of Museums. London; New York: Routledge, 2010.

Simon, Nina. The Art of Relevance. Santa Cruz, CA: Museum 2.0, 2016.

—. The Participatory Museum. Santa Cruz, CA: Museum 2.0, 2010.

Soren, Barbara J. 'Museum Experiences That Change Visitors'. Museum Management and Curatorship 24, no. 3 (2009): 233-251.

Staiff, Russell, Robyn Bushell, and Steve Watson. Heritage and Tourism: Place, Encounter, Engagement. Routledge, 2013.

Stanhope, Zara. 'How to (Read) Things That Don't Exist: Charles Esche in Conversation with Zara Stanhope'. Art Monthly Australia, no. 276 (2014): 34-37.

Stocks, Zachary A. 'Activist Social Work in Small Museums: A Community-Level Exploration'. Master's, University of Washington, 2014.

Teather, J. Lynne. 'Museum Studies: Reflecting on Reflective Practice'. Museum Management and Curatorship 10, no. 4 (1991): 403-417. 
Teather, Lynne, and J. Carter. 'Critical Museology Now: Theory/Practice/Theory'. Muse (Nov./Dec.), 2009, 22-33.

The Dowse Art Museum. 'History'. Accessed 9 March 2018. http://www.dowse.org.nz/about/history.

Tilden, Freeman. Interpreting Our Heritage: Principles and Practices for Visitor Services in Parks, Museums, and Historic Places. Durham, NC: University of North Carolina Press, 1957.

Vergo, Peter. The New Museology. London: Reaktion Books, 1989.

Wayers, Amanda. 'Models, modes and exhibitionary practices: from anteriority to immanence in exhibition development'. Victoria University of Wellington, 2007.

Wells, Marcella D., Barbara H. Butler, and Judith Koke. Interpretive Planning for Museums: Integrating Visitor Perspectives in Decision Making. Walnut Creek, CA: Left Coast Press, Inc, 2012.

Wetterlund, Kris. 'The Voice of Authority'. Journal of Museum Education 37, no. 2 (1 June 2012): 89_ 92.

Whitehead, Christopher. Interpreting Art in Museums and Galleries. 1st ed. Abingdon, Oxon, England; New York, NY: Routledge, 2012.

Wright, Philip. 'The Quality of Visitors' Experiences in Art Museums'. The New Museology, 1989, 119-148.

Yin, Robert. 'How to Do Better Case Studies: (With Illustrations from 20 Exemplary Case Studies)'. In The SAGE Handbook of Applied Social Research Methods, by Leonard Bickman and Debra Rog, 254-82. Thousand Oaks California, United States: SAGE Publications, 2009. 